\title{
Zebrafish-bioassay guided microfractionation identifies anticonvulsant steroid glycosides from the Philippine medicinal plant Solanum torvum
}

Soura Challal $^{1 *}$, Olivia E. M. Buenafe ${ }^{2 *}$, Emerson F. Queiroz ${ }^{1}$, Snezana Maljevic ${ }^{3}$, Laurence Marcourt ${ }^{1}$, Werner Kloeti ${ }^{1}$, Fabian M. Dayrit ${ }^{3}$, Alan L. Harvey ${ }^{5}$, Holger Lerche $^{3}$, Camila V. Esguerra ${ }^{1}$, Peter A. M. de Witte ${ }^{2 * *}$, Jean-Luc Wolfender ${ }^{1 * *}$, Alexander D. Crawford ${ }^{2 * *}$

\begin{abstract}
Affiliation Street, Glasgow G4 0RE, Scotland, UK

*equally contributing first authors

** equally contributing last authors
\end{abstract}

${ }^{1}$ School of Pharmaceutical Sciences, University of Geneva, University of Lausanne, 30, quai ErnestAnsermet, CH-1211 Geneva 4, Switzerland.

${ }^{2}$ Laboratory for Molecular Biodiscovery, Department of Pharmaceutical and Pharmacological Sciences, KU Leuven - University of Leuven, Herestraat 49, 3000 Leuven, Belgium.

${ }^{3}$ Department of Neurology and Epileptology, Hertie Institute for Clinical Brain Research, University of Tübingen, Hoppe-Seyler-Strasse 3, 72076 Tübingen, Germany

${ }^{4}$ Department of Chemistry, Ateneo de Manila University, Loyola Heights, 1108 Quezon City, Philippines ${ }^{5}$ Strathclyde Institute of Pharmacy and Biomedical Sciences, University of Strathclyde, 161 Cathedral

\section{Correspondence}

Prof. Jean Luc Wolfender. School of Pharmaceutical Sciences, University of Geneva, 30, quai ErnestAnsermet, CH-1211 Geneva 4, Switzerland.Tel: +41 2237933 85, Fax: +41 2237933 99. Email: jeanluc.wolfender@unige.ch 


\begin{abstract}
Medicinal plants used for the treatment of epilepsy are potentially a valuable source of novel anti-epileptic small molecules. To identify anticonvulsant secondary metabolites, we performed an in vivo, zebrafish-based screen of medicinal plants used in Southeast Asia for the treatment of seizures. Solanum torvum Sw. (Solanaceae) was identified as having significant anticonvulsant activity in zebrafish larvae with seizures induced by the $\mathrm{GABA}_{\mathrm{A}}$ antagonist pentylenetetrazol (PTZ). This finding correlates well with the ethnomedical use of this plant in the Philippines, where a water decoction of $S$. torvum leaves is used to treat epileptic seizures. HPLC microfractionation in 96-well plates of the bioactive crude extract, in combination with the in vivo zebrafish seizure assay, enabled the rapid localization of several bioactive compounds that were partially identified on-line by UHPLC-TOF-MS as steroid glycosides. Targeted isolation of the active constituents from the methanolic extract enabled the complete de novo structure identification of the six main bioactive compounds that were also present in the traditional preparation. In order to partially mimic the in vivo metabolism of these triterpene glycosides, their common aglycone was generated by acid hydrolysis. The isolated molecules exhibited significant anticonvulsant activity in zebrafish seizure assays. These results underscore the potential of zebrafish bioassay-guided microfractionation to rapidly identify novel bioactive small molecules of natural origin.
\end{abstract}

\title{
Key words
}

Zebrafish, HPLC microfractionation, Solanum torvum, Solanaceae, saponins, anti-epileptic activity. 


\section{Introduction}

Epilepsy is a common neurological disorder characterized by the manifestation of spontaneous seizures as a result of abnormal neuronal activity in the brain. Currently known factors linked to the emergence of epilepsy are stroke, brain injury, brain tumors, infections such meningitis, but in $70 \%$ of cases the cause is not known (WHO, 2012). Epilepsy affects around 65 million people worldwide, especially children, and has a higher prevalence in tropical countries, particularly in Africa (Moshi et al., 2005; Thurman et al., 2011).

Currently, there are a large number of antiepileptic drugs (AEDs), each of them being preferentially used depending on the type of seizure. Importantly, however, almost 30\% of patients suffering from epilepsy remain resistant to these existing treatments (Perucca, 1998). Many currently available AEDs also exhibit serious neurological side effects such as depression, cognitive impairment, and sedation, in addition to other drug-induced toxicities such as gastrointestinal distress and hepatotoxicity (Arif et al., 2009; Arroyo and de la Morena, 2001; Carpay et al., 2005; Schmidt, 2009). For these different reasons there is a clear need to identify new AEDs with efficacy against pharmacoresistant epilepsy and ideally with minimal or no adverse effects.

The identification of new AEDs is a significant challenge due to the heterogeneity and complexity of epileptic seizures. The evaluation of antiepileptic drug leads requires numerious in vitro and in vivo models which mimic the different mechanisms of action involved in epilepsy (Schmidt and Rogawski, 2002). In several in vivo assays, epilepsy is induced after administration of chemical proconvulsants such as the $\mathrm{GABA}_{\mathrm{A}}$ antagonist pentylenetetrazole (PTZ) in rodents (Galanopoulou et al., 2013), and in zebrafish (Danio rerio) (Baraban et al., 2005; Afrikanova et al., 2013). 
In recent years, zebrafish have emerged as a novel experimental model for epilepsy (Baraban et al., 2005). Pentylenetetrazole (PTZ), a proconvulsant widely used to induce absence seizures and generalized tonic-clonic seizures in rodents, induces a dose-dependent series of stereotypical behaviors in 7 day-old zebrafish larvae, including clonus-type convulsions resembling epileptic seizures in mammals (Baraban et al., 2007). Epileptiform discharges were observed from electrophysiological recordings from the brains of PTZ-treated zebrafish larvae, with these discharges reduced by exposure to known anticonvulsant drugs such as valproate and diazepam. In order to facilitate the discovery of novel anti-epileptic drugs, an automated tracking system was developed to monitor the movement of zebrafish larvae in 96-well plates (Berghmans et al., 2007; Orellana-Paucar et al., 2012; Afrikanova et al., 2013; Buenafe et al, 2013). Using this system, we found that similar anti-epileptic drugs were found to suppress PTZ-induced seizurelike behaviors and electrographic activity in both zebrafish and mice, thereby validating the suitability of zebrafish for the high-throughput screening of potential anti-convulsant compounds (Afrikanova et al., 2013).

The general paradigm of using zebrafish as a primary model organism for high-throughput screening in the context of natural-products drug discovery has been gaining ground in the past decade (Crawford et al, 2008, 2011). The advantages of zebrafish as a biological vertebrate model (e.g., fecundity, rapid ex utero development, ease of husbandry, genetic similarities to rodents and humans), when coupled with robust chromatographic and spectroscopic methods, have contributed to discoveries and further development of hit compounds from various plant extracts (Bohni et al., 2013; Buenafe et al., 2013; Orellana-Paucar et al., 2012).

The sharpening focus on exploring plant extracts as sources for novel anticonvulsant drug candidates is not without compelling pretext, such as the historical use of medicinal plants to treat epilepsy (Sucher, 2006; Schachter, 2009), supported by anticonvulsant natural-product 
molecules isolated from such plants to date (Orellana-Paucar et al, 2012 ; Buenafe et al, 2013). The impetus for such efforts can be attributed to the need to address drug-resistant epilepsy and to develop improved AEDs or even botanical therapeutics with reduced neurological and toxicological side effects (Schachter, 2009), especially since the potential of medicinal plants as source of chemical diversity for modern AED discovery cannot be disputed. 


\section{Results and discussion}

\subsection{Zebrafish-based screen of Southeast Asian medicinal plant extracts}

Pre-screening was performed on nine Southeast Asian plants from the University of Strathclyde's natural product library (data not shown), which were selected on the basis of recorded ethnopharmacological use in Philippine pharmacopeia (Quisumbing, 1951). Solanum torvum was chosen for more rigorous assessment. Solanum torvum L. (Solanaceae) is a plant used in traditional medicine in South China and Southeast Asia as a sedative, digestive, hemostatic and diuretic (Zhu et al., 2003). In the Philippines this plant is traditionally used as an antiepileptic and antispasmodic (Quisumbing, 1951). The major constituents of this plant are steroidal saponins, which exhibit various bioactivities including anti-viral, cytotoxic, antimicrobial, and anti-inflammatory (Colmenares et al., 2013; Lee et al., 2013; Lu et al., 2009; Shu et al., 2013). Anticonvulsant activity has previously been reported for solasodine, a steroidal alkaloid isolated from another Solanum species (S. Sisymbriifolium*) (Chauhan et al., 2011). Based on these findings, S. torvum was chosen for further bioactivity analysis, metabolite profiling, and bioassay-guided microfractionation to identify its anticonvulsant constituents.

\subsection{Bioactivity analysis of Solanum torvum}

The aerial parts of S. torvum were successively extracted with solvents of increasing polarity (hexane, dichloromethane, methanol and water) and concentrated under vacuum. The plant was also extracted by water infusion according to the traditional preparation. Zebrafish larvae (at 6.5dpf) were exposed to different concentrations of $S$. torvum crude extracts for $18 \mathrm{~h}$ before subsequent addition of PTZ, which induced seizure-like movement, such as swimming with increasing agitation leading to "whirlpool" behavior, loss of posture and clonus-type movement. The methanolic and water extracts that were likely to be close in composition to the traditional usage of the plant exhibited significant reduction (35-40\%) of PTZ-induced movement in 6/7-dpf 
larvae at $50 \mu \mathrm{g} / \mathrm{ml}(\mathrm{p}<0.05)$, with their maximum tolerated concentrations (MTC) well beyond the highest tested concentration $(200 \mu \mathrm{g} / \mathrm{ml})$ (Figure 1A-D).

\subsection{Metabolite profiling}

The extracts were submitted to metabolite profiling by UHPLC-TOF-MS (Eugster et al., 2011) and their composition was compared (Figure 2). The methanol extract was selected for further chemical study, as it exhibited reduction in PTZ-induced activity in zebrafish larvae at a comparable level to the aqueous extract, and presents a wider array of metabolites. Based on the high resolution (HR)TOF-MS data obtained by metabolite profiling, the molecular formula of the compounds detected in the water infusion could be retrieved. These dereplication data revealed the presence of characteristic steroid glycosides isomers with a high molecular weight as the main LC peaks in the methanolic extract which were previously isolated from this plant (Colmenares et al., 2013; Lee et al., 2013; Lu et al., 2009; Shu et al., 2013). Because of the presence of many isomers known to have various absolute configurations or glycoside substitution patterns, a full structure assignment could not be performed based on such data alone.

\subsection{Bioactivity-guided microfractionation}

In order to rapidly localize the chromatographic zones of the HPLC chromatogram holding the anticonvulsant activity, reversed phase semi-preparative HPLC microfractionation of the crude methanolic extract (122 mg) was performed for metabolite profiling affording nine fractions (F1F9) (Figure 3A) (Wolfender and Queiroz, 2012). Each fraction has been submitted to the zebrafish anticonvulsant bioassay. Fraction 8 showed a significant reduction (35\%) of PTZinduced movement at $50 \mu \mathrm{g} / \mathrm{mL}(*)$ (Figure 3B). The UHPLC-TOF-MS analysis of this active microfraction showed mostly the presence of LC peaks having either a protonated molecules $[\mathrm{M}+\mathrm{H}]^{+}$at $\mathrm{m} / \mathrm{z} 741$ or 727 . This corresponded to isomeric compounds of molecular formula 
$\mathrm{C}_{39} \mathrm{H}_{64} \mathrm{O}_{13}$ or $\mathrm{C}_{38} \mathrm{H}_{62} \mathrm{O}_{13}$. Such data matched well with previously isolated steroid glycosides from this plant (Colmenares et al., 2013; Lee et al., 2013; Lu et al., 2009; Shu et al., 2013). A differentiation of the various isomers present could however not be made based on MS data only. This rapid fractionation with only a few tenth of $\mathrm{mg}$ of crude extract however indicated that the steroid glycosides were responsible for the anticonvulsant activity of the extract measure in the in vivo assays.

In order to fully characterize the active compounds and assess their activities quantitatively their isolation at a larger scale was needed. The separation was optimized by HPLC-UV-ELSD-MS. This procedure capitalizes on the HPLC modeling based on generic linear gradients at the analytical level to maximize the separation of interest compounds. These optimized analytical HPLC conditions were then transferred to medium pressure liquid chromatography (MPLC-UVELSD) using the same $\mathrm{C}_{18}$ reverse stationary phase $\left(\right.$ Zeoprep $\left.^{\circledR}\right)$ and the same particle size (15-25 $\mu \mathrm{m})$. Using this approach, 6 compounds were isolated in one step at the mg scale (Figure 4).

\subsection{Structural elucidation of the bioactive compounds}

Four compounds (1-4) displayed the same molecular formula $\left(\mathrm{C}_{39} \mathrm{H}_{64} \mathrm{O}_{13}\right)$ assigned from their ESI-HRMS positive ion at $\mathrm{m} / \mathrm{z}, 741.4446$ (eg for Torvoside J) (calcd. for $\mathrm{C}_{39} \mathrm{H}_{65} \mathrm{O}_{13}[\mathrm{M}+\mathrm{H}]^{+}$: 741.4425). According to the Dictionary of Natural Products (The Chapman and Hall Dictionary of Natural Products on DVD, CRC Chemical Database), seven compounds, with the same spirostane skeleton, were found in the genus Solanum with this molecular formula. Namely, Torvoside $\mathrm{C}$ (this one was revised to Torvoside $\mathrm{K}$ by Iida et al., 2005), Torvoside J-L,

Paniculonin B, Spirotorvoside and Melongoside E. The ${ }^{1} \mathrm{H}$ NMR spectra of 1-4 showed a very similar pattern in agreement with glycosylated spirostane: two methyl singlets (Me-18 and Me19), four methyl doublets, two belonging to the spirostane (Me-21 and Me-27) and two to the sugars moieties (Me-6' and Me-6") and two anomeric doublets at $\delta_{\mathrm{H}} 5.14\left(\mathrm{~J}=1.7 \mathrm{~Hz}, \mathrm{H}-1^{\prime}\right)$ and 
$4.27\left(J=7.9 \mathrm{~Hz}, \mathrm{H}-1^{\prime \prime}\right)$. The COSY, TOCSY and HSQC spectra allowed identifying the sugars as a quinovose and a rhamnose. The long range $\mathrm{HMBC}$ correlations from $\mathrm{H}-3$ ' of the quinovose $\left(\delta_{\mathrm{H}} 3.42, \mathrm{t}, J=8.9 \mathrm{~Hz}\right)$ to $\mathrm{C}-1$ " of the rhamnose $\left(\delta_{\mathrm{C}} 102.8\right)$ and from $\mathrm{H}-1$ ' of the quinovose to C-6 of the spirostane $\left(\delta_{\mathrm{C}} 80.4\right)$ indicated that the four compounds belong to the following type: 3 $\beta, 6 \alpha, 23$-trihydroxy-5 $\alpha$-spirostane 6-O- $\beta$-D-rhamnopyranosyl-(1 $\rightarrow 3)-\mathrm{O}-\beta$-D-quinovopyranosyl. Melongoside E and Spirotorvoside being spirostane 3-O-glycoside they were thus excluded from the list of possible structures. At this stage, Torvoside J, K, L and Paniculonon B remain the four possible structures which differ only from their configuration at C-22, C-23 and C-25. According to Y. Iida et al. (Chem. Pharm. Bull. 2005) the $\delta_{\mathrm{C}}$ at C-20 and $\delta_{\mathrm{H}}$ at Me-21 (in pyridine-d5) are diagnostic for the determination of the configuration at C-22: $\delta_{\mathrm{H}} 1.07-1.26$ and $\delta_{\mathrm{C}} 35.0-36.2$ for 22- $\alpha$-O-spirostanol (22-S) and $\delta_{\mathrm{H}} 1.53-1.54$ and $\delta_{\mathrm{C}} 43.1-44.1$ for $22-\beta$-O-spirostanol (22-R). As the NMR data have been recorded in $\mathrm{CD}_{3} \mathrm{OD}$ (the solvent used for the dereplication database) a direct comparison with the reported data was not possible. However, compounds 1, 2, 3 and 4 could be split into two groups based on their chemical shift values at $\mathrm{C}-20$ and $\mathrm{Me}-21$. The ${ }^{13} \mathrm{C}$ chemical shifts recorded in $\mathrm{CD}_{3} \mathrm{OD}$ being very close to those obtained in pyridine-d5, we concluded that $\mathbf{1}, 2$ and 3 were $22-\mathrm{R}$ with the following $\delta_{\mathrm{H}}(\mathrm{Me}-21) / \delta_{\mathrm{C}}(\mathrm{C}-20)$ : $1.10 / 41.6$, $1.12 / 40.8$ and $1.16 / 43.6$ whereas 4 exhibited a $22-\mathrm{S}$ configuration $\left(\delta_{\mathrm{H}}(\mathrm{Me}-21) / \delta_{\mathrm{C}}(\mathrm{C}-20)\right.$ : 0.96/37.0). The configuration of C-23 could be deduced from the H-23 coupling constant ( $\mathrm{dd}(J$ $=10.3 / 5.2 \mathrm{~Hz})$ when $\mathrm{H}-23$ was in axial position and a triplet $(J=3 \mathrm{~Hz})$ when $\mathrm{H}-23$ was in equatorial position). The configuration at C-25 was usually determined by the signal pattern of H-26 $(\operatorname{brd}(J=11.0 \mathrm{~Hz})$ and dd, $(J=11.0,3.0 \mathrm{~Hz})$ when $\mathrm{H}-25$ is equatorial and $\mathrm{t}(J=11.0 \mathrm{~Hz})$ and brd, $(J=11.0 \mathrm{~Hz})$ when $\mathrm{H}-25$ is axial $)$. The $\delta_{\mathrm{H}}$ of Me-27 was also characteristic as it appear shifted downfield in axial position (1.10-1.16) compared to the equatorial position (0.77-0.82). Based on these observations, compound $\mathbf{1}$ was unambiguously identified as Torvoside $\mathbf{J}$ (22R, 23S, 25S), 2 as Torvoside L (22R, 23R, 25S), 3 as Torvoside K (22R, 23S, 25R) (Y. Iida et al. 
Chem. Phar. Bull. 2005) and 4 to Paniculonin B (22S, 23S, 25S) (C-L. Lee et al. Phytochem 1995).

The other isolated compounds (5 and 6) shared a same molecular $[\mathrm{M}+\mathrm{H}]^{+}$ion at $(\mathrm{eg} \mathrm{m} / \mathrm{z}$ 727.4302 for Paniculonin A) (calcd. for $\mathrm{C}_{38} \mathrm{H}_{63} \mathrm{O}_{13}[\mathrm{M}+\mathrm{H}]^{+}$: 727.4269) indicating a molecular formulae of $\mathrm{C}_{38} \mathrm{H}_{62} \mathrm{O}_{13}$ shifted by $14 \mathrm{Da}$ compare to 1-4. The ${ }^{1} \mathrm{H}$ NMR spectrum of 5 was very close to that of Torvoside $\mathbf{J}(\mathbf{1})$ at the exception of the sugar region. The missing methyl doublet at $\delta_{\mathrm{H}} 1.25\left(\mathrm{CH}_{3}-6 "\right)$ in $\mathbf{1}$ and the lack of $\mathrm{CH}_{2}$ in the molecular formulae suggested the presence of a pentose instead of a hexose. The second sugar was identified as a xylose $\left(\delta_{H} / \delta_{C} 4.48 / 106.0\right.$ for H/C-1", 3.26/75.3 for H/C-2", 3.33/77.7-3 for H/C-3", 3.49/71.0 for H/C-4" and 3.23,3.90/67.1

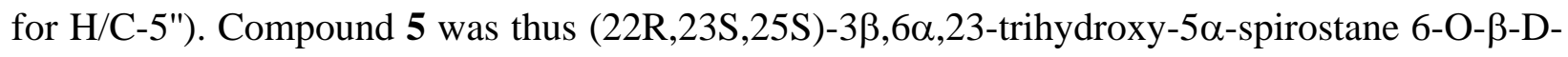
xylopyranosyl-(1 $\rightarrow 3$ )-O- $\beta$-D-quinovopyranoside (Lu et al. Phytochem 2011$)$. The ${ }^{1} \mathrm{H}$ NMR of 6 displayed the same sugar pattern as $\mathbf{5}$ and the same spirostane pattern as Paniculonin B (4). Compound 6 was elucidated as Paniculonin A (M. Gonzalez et al. J. Nat. Prod. 2004). The NMR description of all these compounds have not yet been reported in $\mathrm{CD}_{3} \mathrm{OD}$, which is a common solvent used for at-line dereplication by micro-NMR methods, and they are thus detailed in the experimental section.

\subsection{Acid hydrolysis of the glycosides}

Triterpene glycosides are known to have poor intestinal absorption mainly due to their unfavorable physicochemical properties, such as large molecular mass (>500 Da), high hydrogen-bonding capacity (>12), and high molecular flexibility $(>10)$, that underlie poor membrane permeability (Yu et al., 2012). Assuming that the isolated steroid glycosides from $S$. torvum may be pro-drugs, the fraction containing the triterpene glycosides was submitted to a mild acid hydrolysis (refluxed with $2 \% \mathrm{H}_{2} \mathrm{SO}_{4} / \mathrm{MeOH}$ for 8 days at $37^{\circ} \mathrm{C}$ ) to provide the corresponding aglycones (Kesselmeier and Budzikiewicz, 1979) that could mimic an initial 
degradation step in the stomach (Yu et al., 2012). The hydrolysis afforded mainly one compound $\left(\mathrm{C}_{22} \mathrm{H}_{34} \mathrm{O}_{4}\right)\left([\mathrm{M}+\mathrm{H}]^{+}\right.$at $m / z 363.2543$ (calculated for $\left.\left.\mathrm{C}_{22} \mathrm{H}_{34} \mathrm{O}_{4}, 363.2535,2.2 \Delta \mathrm{ppm}\right)\right)$. The NMR analysis of the HSQC spectrum of the hydrolyzed product revealed the absence of sugar signals as well as the characteristic signals belonging to the spirostane ring (eg. the oxymethine $\mathrm{CH}-23$ and oxymethylene $\mathrm{CH}_{2}-26$ ). Moreover, a careful analysis of signals indicated that the hydrolyzed product consist of a 65/35 mixture of two aglycones as seen by the duplication of signals for $\mathrm{H}-$ $16\left(\delta_{\mathrm{H}} / \delta_{\mathrm{C}} 5.03 / 84.6\right.$ and $\left.4.83 / 84.1\right), \mathrm{H}-20\left(\delta_{\mathrm{H}} / \delta_{\mathrm{C}} 2.60 / 37.4\right.$ and $\left.2.97 / 38.7\right), \mathrm{H}-17\left(\delta_{\mathrm{H}} / \delta_{\mathrm{C}} 1.98 / 59.9\right.$ and 22.31/56.6), Me-21 $\left(\delta_{\mathrm{H}} / \delta_{\mathrm{C}} 1.28 / 17.9\right.$ and 1.30/10.3) and Me-18 $\left(\delta_{\mathrm{H}} / \delta_{\mathrm{C}} 0.73 / 13.9\right.$ and 0.81/14.0). Despite these differences in chemical shifts, the HMBC correlations were the same in both molecules: from Me-21 to C-17, C-20 and the ester carbonyl at $\delta_{\mathrm{C}} 183.9 / 182.2$ and from Me-18 to C1-2, C-13, C-14 and C-17. The two aglycones were thus epimers. Analysis of the NOESY correlations indicated that the first one was solanolide (A.K. Chakravarty et al. Phytochemistry, 1982) as seen by the dipolar correlation from H-16 to Me-21 and H-17 and from H-20 and Me-18. For the second isomer, the NOE crosspeaks from H-16 to H-17 and H-20 and from Me-21 to Me-18 showed that it was the epimer of solanolide at C-20. The mechanism for production of these aglycones (7a and $\mathbf{7 b}$ ) was already speculated for the study of similar compounds in Solanum anguivi (Nafady et al., 2003).

\subsection{Bioactivity analysis of isolated compounds in vivo}

The six isolated S. torvum steroidal glycosides and the aglycone from acid-hydrolysis (compounds 1-7) were subjected to further biological activity analyses. The selected compounds were exposed to 6/7-dpf zebrafish larvae for $18 \mathrm{~h}$ in various concentrations, with their MTC values beyond the highest concentration $(280 \mu \mathrm{M}$, with the exception of compound $\mathbf{1}$, which was at $140 \mu \mathrm{M}$ ), before subsequent exposure to $20 \mathrm{mM}$ PTZ (Figure 5). Compounds 4 - 6 did not show significant reduction in PTZ-induced locomotor activity in larvae (Figure 5-4, 5-5, 5-6). Inconsistent reduction of PTZ-induced activity over the 30-minute exposure time was seen for 
compounds 2 and 3 (Figure 5-2,5-3), although they display reduction of total movement only at $70 \mu \mathrm{M}$ (Figure 5-7). Compound 1 showed significant reduction of PTZ-induced activity from 70 $\mu \mathrm{M}$ (moderate, $\mathrm{P}<0.05)$ until $140 \mu \mathrm{M}(\mathrm{P}<0.001)$ (Figure 5-1). As these compounds have similar structures, the slight difference in compound $\mathbf{1}$ (the stereochemical positions of $-\mathrm{OH}$ and $-\mathrm{CH}_{3}$ in the spirostane ring) compared to the other identified torvosides $(\mathbf{2 , 3})$ may play a role in activity modulation, as well as the type of sugar moiety attached to the aglycone (5) (Figure 4). However, significant reduction of PTZ-induced activity in larvae was also observed for acidhydrolysis aglycone 7 at its MTC value $(140 \mu \mathrm{M})$ (Figure 6A), indicating that the presence of a sugar moiety may not be necessary.

The structures of the steroidal glycosides isolated from $S$. torvum, especially their acidhydrolysis aglycone product, bear resemblance to neurosteroids (e.g., alphaxalone, pregnanolone, allopregnanolone, ganaxolone) which are known to interact with GABA receptors, and have been used as anesthetics and sedatives (Child et al, 1971; Lan, 1994). One such neurosteroid, ganaxolone, a potent $\mathrm{GABA}_{\mathrm{A}}$ modulator, shows anticonvulsant properties (Carter et al., 1997) and is now facing Phase III clinical trials (Bialer et al, 2013) on adult patients suffering from partial seizures. Based on the similarity of structure to the isolated compounds and its known pharmacology and mode of action, ganaxolone was selected as a reference drug for comparison purposes in larval zebrafish PTZ assays. Upon exposure to larval zebrafish prior to addition of PTZ, ganaxolone (8) has shown to significantly reduce the influence of PTZ on the locomotor activity of 7-dpf zebrafish larvae at $0.3 \mathrm{nM}$ (Figure 6B). Comparing the reduction of PTZ-induced activity of ganaxolone with any of the isolated $S$. torvum compounds (and aglycone), we observed that there is a large difference in the order of magnitude in terms of potencies of the compounds. 


\subsection{Bioactivity analysis of isolated compounds in vitro}

Since neurosteroids are known to be $\mathrm{GABA}_{\mathrm{A}}$ modulators and the aglycone (7) present a related steroid structural type, we used Xenopus laevis oocyte expression system to test the effects of different compounds on the activity of $\mathrm{GABA}_{\mathrm{A}}$ receptors comprising $\alpha 1, \beta 2$, and $\gamma 2 \mathrm{~s}$ subunits (Abdullah and Zhang, 2013). To check the expression level a test pulse with 1mM GABA was applied at the beginning of each recording. After thorough washing $10 \mu \mathrm{M}$ ganaxolone, pregnanolone, S. torvum crude extract or compound 7 were applied and the obtained response normalized to the test pulse. Pregnanolone, the crude extract and the aglycone (7) produced smaller currents compared to the currents generated by ganaxolone (8). All novel compounds elicited currents resembling the ones induced by GABA (Figure 7A, B).

In a different set of experiments we examined the potentiation effect on $\mathrm{GABA}_{\mathrm{A}}$ receptor response known for pregnanolone and allopregnanolone (Reddy, 2010). Here the first application of $10 \mu \mathrm{M}$ GABA was followed by application of $10 \mu \mathrm{M}$ GABA mixed with $10 \mu \mathrm{M}$ or $100 \mu \mathrm{M}$ of each tested compound. Washing times in between applications was 5 minutes and all responses were normalized to the current produced by $10 \mu \mathrm{M}$ GABA in the same cell. Except for application of $10 \mu \mathrm{M}$ GABA together $100 \mu \mathrm{M}$ pregnanolone, all other currents were 2-3 fold reduced compared to the ones generated by $10 \mu \mathrm{M}$ GABA. These results indicate that the isolated compounds from S. torvum are weak modulators of GABA receptors compared to ganaxolone or pregnanolone.

The disparate order of magnitude of difference in potencies (sub-nanomolar vs micromolar) between ganaxolone and the S. torvum aglycone (or even the parent steroidal glycosides) in the larval zebrafish assay may be accounted for the structural differences between them. The fundamental criterion for a neurosteroid to be effective in modulating GABA receptors is that the compound should possess a hydrogen bond donor at C-3 in the steroid skeleton $(3 \alpha-\mathrm{OH})$, coupled with a hydrogen bond acceptor at C-17 on the $\beta$ plane of the skeleton (Covey, 2001; 
Akk, 2007). Beside being of the same structural type as ganaxolone, the acid-hydrolyzed aglycone (7) exhibited several main differences such as $3 \beta-\mathrm{OH}$ instead of the alpha configuration, a furan-type ring fused at $\mathrm{C} 16-\mathrm{C} 17$ instead of a $\mathrm{COCH}_{3}$ at $\mathrm{C} .17$ and altogether this may explain a different mode of action for both molecules.

The results obtained indicate, based on the hypothesis of a possible link between the mode of actions of ganoxolone and the steroids of $S$. torvum, that the isolated compounds are not equally as potent as ganaxolone as $\mathrm{GABA}_{\mathrm{A}}$ modulators, as reflected by the larval zebrafish results as well as from the $X$. laevis oocyte receptor overexpression system. It can thus be hypothesize that the reduction of PTZ-induced activity of $S$. torvum extract and compounds may be due to mechanisms other than the GABA inhibitory system. 


\section{Conclusion}

This work presents a new strategy of combining HPLC micro-fractionation with at-line bioactivity assessment on an in vivo zebrafish behavioral epilepsy assay. It has allowed an efficient localization of bioactive steroid glycoside and served for an efficient targeted isolation of the bioactive compounds.

The isolation procedure was performed by direct geometrical gradient transfer from analytical HPLC-ELSD to preparative medium pressure liquid chromatography (MPLC-ELSD) and allowed an efficient isolation of the active compounds at large amount. The bioguided isolation afforded six spirostane glycosylated triterpenes that were responsible for the antiepileptic activity of the infusion and methanolic extract of aerial parts of Solanum torvum. These compounds presented anticonvulsant activity in the in vivo zebrafish model but no specificity was recorded among the different glycoside tested. Since the presumed bioavailability of such compounds is poor and they might undergo hydrolysis when taken orally, as it the case with the traditional preparation, we demonstrated that these compounds could generate an active aglycone through a skeleton rearrangement under mild hydrolysis conditions. Despite the structural resemblance to neurosteroids such as ganaxolone, these isolated steroidal glycosides and aglycone offer only weak GABA modulation, thus indicating that these compounds may act on a different mechanism of action to significantly reduce PTZ-induced seizure activity in zebrafish. 


\section{Materials and methods}

General Experimental Procedures. NMR spectroscopic data were recorded on a $500 \mathrm{MHz}$ Agilent/Varian Inova spectrometer. Chemical shifts are reported in parts per million $(\delta)$ using the residual $\mathrm{CD}_{3} \mathrm{OD}$ signal $\left(\delta_{\mathrm{H}} 3.31 ; \delta_{\mathrm{C}} 49.0\right)$ as internal standards for ${ }^{1} \mathrm{H}$ and ${ }^{13} \mathrm{C} \mathrm{NMR}$, and coupling constants $(\mathrm{J})$ are reported in Hz. Complete assignment was performed based on 2D experiments (COSY, TOCSY, NOESY, edited-HSQC and HMBC). ESI-HRMS data were obtained on a Micromass LCT Premier time-of-flight mass spectrometer from Waters with an electrospray ionization (ESI) interface (Waters, Milford, MA, USA). Analytical HPLC was performed using an HP 1100 system equipped with a photodiode array detector (Agilent Technologies, Santa Clara, CA, USA). MPLC was performed using a Büchi 681 pump (Büchi, Flawil, Switzerland) equipped with a Knauer UV detector (Knauer, Berlin, Germany) and a 920 x 49 mm i.d. column (Büchi, Flawil, Switzerland) loaded with ZEOprep® C18 as the stationary phase 15-25 $\mu \mathrm{m}$ (Zeochem, Uetikon am See, Switzerland).

Plant material. The aerial parts of Solanum torvum was collected in Infanta, Quezon in the Philippines in 2011. The botanical material was properly identified, with voucher specimen \#2796, deposited in the Herbarium of the Institute of Biology of the University of the Philippines (UP Diliman). A Material Transfer Agreement for the collection and transfer of S. torvum material from the Philippines to Belgium, in concordance with the UN Convention on Biodiversity, has been signed between KU Leuven and Ateneo de Manila University.

Preparation of extract. The dried aerial parts (102.24 g) were successively extracted under maceration and agitation with increasing polarity extraction in a round-bottom flask using a sequence of solvents of increasing polarity (hexane, dichloromethane, methanol and water) and concentrated under vacuum to yield $2.15 \mathrm{~g}$ of hexane $(2.1 \%), 1.73 \mathrm{~g}(1.7 \%)$ of dichloromethane, and $13.59 \mathrm{~g}$ of methanol (13.3\%). The aqueous extract was frozen and lyophilized yielding 1.83 
$\mathrm{g}(1.8 \%)$ of water extract. Traditional decoction has been prepared using $10 \mathrm{~g}$ of dried aerial part of $S$. torvum in $100 \mathrm{ml}$ of hot water during 1 hour a comparison of the profile with simple infusion for example revealed the presence of similar compounds. The solution is filtrate and evaporated to dryness yield $1.6 \mathrm{~g}(16 \%)$.

HPLC-DAD-ELSD-MS Analysis.HPLC-DAD-ELSD-MS data were obtained with an Agilent HP 1100 series system consisting of an autosampler, high-pressure mixing pump and DAD detector (Agilent Technologies, Santa Clara, CA, USA) connected to a Finnigan MAT LCQ ion trap mass spectrometer (Finnigan, San Jose, CA, USA) equipped with a Finnigan electrospray interface (ESI) and a ELSD detector Sedex 85 (Sedere, Oliver, France). The HPLC conditions were as follows: an Zeoprep® C-18 column $(15-25 \mu \mathrm{m}, 250$ x $4.6 \mathrm{~mm}$ i.d. (this particle size was selected for an optimum gradient transfert the MPLC) (Zeochem, Uetikon am See, Switzerland); solvent system: $\mathrm{A}, \mathrm{H}_{2} \mathrm{O}$ containing $0.1 \%$ formic acid and $\mathrm{B}, \mathrm{ACN}$ containing $0.1 \%$ formic acid; step gradient: 2 to $27 \%$ of B in 5 min followed by $27 \%$ of B for $20 \mathrm{~min}$, then $27 \%$ B to $36 \%$ of B in $5 \mathrm{~min}$, followed by $36 \% \mathrm{~B}$ for $20 \mathrm{~min}$ and $36 \%$ to $95 \%$ of $\mathrm{B}$ in $10 \mathrm{~min}$; flow rate: $1 \mathrm{ml} \mathrm{min}^{-1}$; injection volume: $10 \mu \mathrm{l}$; and sample concentration: $10 \mathrm{mg} / \mathrm{ml}$ in $\mathrm{MeOH}$. The samples are analysed with UV detection and the absorbance was measured at $280 \mathrm{~nm}$ and ELSD detection. ESI-MS conditions were as follows: capillary voltage: $30 \mathrm{~V}$; capillary temperature: $200{ }^{\circ} \mathrm{C}$; source voltage: $4.5 \mathrm{kV}$; source current: $80 \mu \mathrm{A}$; nitrogen as the sheath gas; and positive and negative ion mode. Spectra (180-1200 mu) were recorded every $3 \mathrm{~s}$.

UHPLC-TOF-HRMS analyses. HRMS metabolite fingerprint of the extracts was performed on a Micromass-LCT Premier Time of Flight (TOF) mass spectrometer (Waters, Milford MA, USA) equipped with an electrospray interface and coupled to an Acquity UPLC system (Waters, Milford MA, USA). The ESI conditions were as follows: capillary voltage $2800 \mathrm{~V}$, cone voltage $40 \mathrm{~V}$, MCP detector voltage $2400 \mathrm{~V}$, source temperature $120^{\circ} \mathrm{C}$, desolvation temperature $300^{\circ} \mathrm{C}$, cone gas flow $20 \mathrm{~L} / \mathrm{h}$, and desolvation gas flow $600 \mathrm{~L} / \mathrm{h}$. Detection was performed in positive ion 
mode (PI) with a m/z range of $100-1300 \mathrm{Da}$ and a scan time of $0.5 \mathrm{~s}$ in the $\mathrm{W}$-mode. The MS was calibrated using sodium formate, and leucine encephalin (Sigma-Aldrich, Steinheim, Germany) was used as an internal reference at $2 \mu \mathrm{g} / \mathrm{mL}$ and infused through a Lock Spray ${ }^{\mathrm{TM}}$ probe at a flow rate of $10 \mu \mathrm{L} / \mathrm{min}$ with the help of a second LC pump.

The general profiling of the extract was performed on a Acquity BEH C18 UPLC column (150 $\times 2.1 \mathrm{~mm}$ i.d.; $1.7 \mu \mathrm{m}$, Waters, Milford, MA, USA) using a linear gradient from 5\% ACN+0.1\% FA to $95 \%$ of $\mathrm{B}$ in $30 \mathrm{~min}$, while for the separation of the isomers the following otpimised conditions were used:Acquity BEH C18 UPLC column $(50 \times 2.1 \mathrm{~mm}$ i.d.; $1.7 \mu \mathrm{m}$, Waters, Milford, MA, USA) using a stepgradient (solvent system: $\mathrm{A}=0.1 \%$ formic acid-water, $\mathrm{B}=0.1 \%$ formic acid-acetonitrile; gradient: $5-36 \% \mathrm{~B}$ in $1 \mathrm{~min}$, then $36 \% \mathrm{~B}$ to $36 \% \mathrm{~B}$ in $2 \mathrm{~min}, 36 \% \mathrm{~B}$ to $95 \% \mathrm{~B}$ in $1.5 \mathrm{~min}$; flow rate $1.1 \mathrm{ml} / \mathrm{min}$ ). The temperature was set to $40^{\circ} \mathrm{C}$. The injected volume was kept constant $(1 \mu \mathrm{L})$.

Semi preparative HPLC-UV microfractionation. A first fractionation allowed the localisation of the active area on the chromatogram. The fractionation was performed on a5 $\mu \mathrm{m}$ Xterra prep Column C18 OBD $(150 x 19 \mathrm{~mm}, 5 \mu \mathrm{m})$. The gradient start with $100 \%$ of mobile phase A $\left(\mathrm{H}_{2} \mathrm{O}+0.1 \%\right.$ FA) to $60 \%$ of mobile phase $\mathrm{B}(\mathrm{ACN}+0.1 \%$ FA) in 56 min.13 Fractions were collected every 3 minutes were the separation couls be monitored by UV. Fraction 1 has been obtained by pooling 3 successives fractions, F4 and F5 by pooling 2 successives fractions. The non UV active part was pooled into two main fractions (F8 and F9).

Isolation of active compounds from the methanolic extract. The methanolic extract (4 g) was first fractionated using MPLC with Zeoprep ${ }^{\circledR}$ C18 as the stationary phase $(15-25 \mu \mathrm{m}, 920$ x 49 mm i.d.) (Zeochem, Uetikon am See, Switzerland) $\mathrm{ACN}$ and $\mathrm{H}_{2} \mathrm{O}$ containing $0.1 \%$ formic acid as mobile phase in a step gradient as the following: 2-27\% B for 9.5 hours, isocratic $27 \%$ B for 31.5 hours, $27-36 \%$ B for 8 hours, isocratic $36 \%$ for 32 hours, $36-95 \%$ B for 16 hours, isocratic 
95\% B for 16 hours for 113 hours as a total of purification time. The flow rate was $4 \mathrm{ml} \mathrm{min}{ }^{-1}$, and the UV absorbance was detected at $280 \mathrm{~nm}$. The ELSD detection was performed under the following parameters: pressure 3.2 bars, $45^{\circ} \mathrm{C}$, split to provide a $500 \mu \mathrm{l} / \mathrm{min}$ Flow rate, gain 8 . The MPLC yielded 182 fractions. All fractions were analysed by UHPLC-TOF-MS. Fraction 71 yielded compound 1, Torvoside $\mathrm{J}$ (9.4 mg), fraction 80 yielded 2, F80 (3.4 mg), fraction 88A yielded 3, Torvoside K (7 mg), fraction 88B yielded 4, Torvoside L (7 mg), fraction 117 yielded 5 Paniculin B (2.2 mg), and fraction 128 yielded 6, Paniculin A (1.6 mg) all the other fractions were selected for further purification.

Hydrolysis conditions for obtaining the aglycone 7. In order to obtain the aglycone from the spirostane glycoside, a mild hydrolysis has been performed. Indeed, classical acidic hydrolysis induces a destruction of the spirostane. The mild hydrolysis protocol was based on the one described by Kesselmeier et al., in 1979 except the $\mathrm{HCl}$ has been replaced by $\mathrm{H}_{2} \mathrm{SO}_{4}$. Aglycone was obtained by subjecting glycoside of interest to a solution $2 \% \mathrm{H}_{2} \mathrm{SO}_{4}$ in $\mathrm{MeOH}$ at $37^{\circ} \mathrm{C}$ during 8 days.

\section{Spectral data of the isolated compounds}

Compound 1, Torvoside J. H NMR ( $\left.\mathrm{CD}_{3} \mathrm{OD}, 500 \mathrm{MHz}\right) \delta 0.68(1 \mathrm{H}, \mathrm{td}, J=11.3,3.6 \mathrm{~Hz}, \mathrm{H}-9)$, 0.77 (3H, d, J=6.6 Hz, Me-27), 0.81 (3H, s, Me-18), 0.87 (3H, s, Me-19), 0.95 (1H, m, H-7b), 1.02 (1H, m, H-1b), 1.10 (3H, d, J=6.9 Hz, Me-21), 1.13 (1H, m, H-12b), 1.15 (2H, m, H-4b, H5), 1.16 (1H, m, H-14), 1.25 (3H, d, J=6.2 Hz, Me-6"), 1.27 (1H, m, H-15b), 1.28 (3H, d, J=6.2 Hz, Me-6'), 1.32 (1H, m, H-11b), 1.41 (1H, m, H-2b), 1.54 (1H, m, H-11a), 1.61 (1H, m, H-24b), 1.64 (1H, m, H-8), 1.66 (1H, m, H-24a), 1.69 (1H, m, H-17), 1.70 (1H, m, H-1a), 1.74 (1H, m, H-12a), 1.75 (1H, m, H-2a), 1.98 (1H, m, H-15a), 2.04 (1H, m, H-25), 2.17 (1H, dt, J=12.5, 4.1 Hz, H-7a), 2.25 (1H, p, J=6.9 Hz, H-20), 2.38 (1H, m, H-4a), 3.02 (1H, t, J=8.9 Hz, H-4'), 3.28 (1H, dd, J=8.9, 7.9 Hz, H-2'), 3.31 (1H, m, H-5'), 3.36 (1H, m, H-26b), 3.38 (1H, m, H-6), 3.40 $(1 \mathrm{H}, \mathrm{t}, J=9.6 \mathrm{~Hz}, \mathrm{H}-4 "), 3.43$ (1H, t, J=8.9 Hz, H-3'), 3.46 (2H, m, H-3, H-26a), 3.53 (1H, t, $J=3.0 \mathrm{~Hz}, \mathrm{H}-23), 3.70$ (1H, dd, $J=9.6,3.3 \mathrm{~Hz}, \mathrm{H}-3 "), 3.94$ (1H, brs, H-2"), 3.99 (1H, dq, $J=9.6$, $6.2 \mathrm{~Hz}, \mathrm{H}-5 "), 4.27$ (1H, d, J=7.9 Hz, H-1'), 4.46 (1H, q, J=6.9 Hz, H-16), 5.14 (1H, brs, H- 
$1 "){ }^{13} \mathrm{C}$ NMR $\left(\mathrm{CD}_{3} \mathrm{OD}, 126 \mathrm{MHz}\right) \delta 13.9$ (C-19), 16.8 (C-18), 17.1 (C-21), 17.4 (C-27), 17.9 (C6"), 18.4 (C-6'), 22.0 (C-11), 24.9 (C-25), 31.8 (C-2), 32.7 (C-4), 32.9 (C-15), 35.2 (C-8), 37.5 (C-10), 37.6 (C-24), 38.4 (C-1), 40.7 (C-12), 41.6 (C-7, C-20), 42.0 (C-13), 51.7 (C-5), 55.0 (C9), 57.4 (C-14), 65.6 (C-17), 67.5 (C-26), 70.0 (C-5"), 71.0 (C-23), 71.8 (C-3), 72.2 (C-3"), 72.3 (C-2"), 72.9 (C-5'), 73.9 (C-4"), 75.7 (C-4'), 76.3 (C-2'), 80.3 (C-6), 82.3 (C-16), 84.2 (C-3'), 102.7 (C-1"), 105.1 (C-1'), 109.9 (C-22). ESI-HRMS m/z $741.4437[\mathrm{M}+\mathrm{H}]^{+}$(calculated for $\mathrm{C}_{39} \mathrm{H}_{65} \mathrm{O}_{13}, 741.4425, \Delta \mathrm{ppm}=1.6$ )

Compound 2, Torvoside L. ${ }^{1} \mathrm{H}$ NMR $\left(\mathrm{CD}_{3} \mathrm{OD}, 500 \mathrm{MHz}\right) \delta 0.69$ (1H, m, H-9), 0.82 (3H, d, $J=6.4 \mathrm{~Hz}, \mathrm{Me}-27$ ), 0.87 (3H, s, Me-18), 0.88 (3H, s, Me-19), 0.94 (1H, q, J=12.2Hz, H-7b), 1.02 (1H, brt, J=12.7 Hz, H-1b), 1.12 (1H, m, H-14), 1.14 (1H, m, H-4b), 1.16 (2H, m, H-5, H-12b), $1.16(3 \mathrm{H}, \mathrm{d}, J=7.2 \mathrm{~Hz}, \mathrm{Me}-21), 1.24$ (3H, d, J=6.2 Hz, Me-6"), 1.28 (1H, m, H-15b), 1.28 (3H, d, $J=6.2 \mathrm{~Hz}, \mathrm{Me}-6$ '), 1.35 (1H, m, H-11b), 1.41 (1H, m, H-2b), 1.48 (1H, q, J=11.8Hz, H-24b), 1.55 (1H, d, J=13.7 Hz, H-11a), 1.66 (1H, m, H-8), 1.71 (1H, m, H-1a), 1.74 (1H, m, H-12a), 1.75 (2H, m, H-2a, H-25), 1.79 (1H, m, H-24a), 1.84 (1H, dd, J=9.1, 6.3 Hz, H-17), 1.96 (1H, dq, $J=12.1,6.5 \mathrm{~Hz}, \mathrm{H}-15 \mathrm{a}), 2.17$ (1H, m, H-7a), 2.20 (1H, m, H-20), 2.38 (1H, m, H-4a), 3.02 (1H, t, $\left.J=9.1 \mathrm{~Hz}, \mathrm{H}-4^{\prime}\right), 3.26$ (1H, dd, $\left.J=9.3,8.0 \mathrm{~Hz}, \mathrm{H}-2^{\prime}\right), 3.30,(1 \mathrm{H}, \mathrm{m}, \mathrm{H}-26 \mathrm{~b}), 3.31\left(1 \mathrm{H}, \mathrm{m}, \mathrm{H}-5^{\prime}\right)$, 3.39 (2H, m, H-6, H-4"), 3.42 (1H, m, H-3'), 3.43 (1H, m, H-26a), 3.45 (1H, m, H-3), 3.63 (1H, dd, $J=11.5,4.6$ Hz, H-23), 3.69 (1H, dd, J=9.5, 3.4 Hz, H-3"), 3.93 (1H, dd, J=3.4, $1.8 \mathrm{~Hz}, \mathrm{H}-$ 2"), 3.99 (1H, m, H-5"), 4.27 (1H, d, J=8.0 Hz, H-1'), 4.71 (1H, q, J=7.6 Hz, H-16), 5.14 (1H, d, $J=1.8 \mathrm{~Hz}, \mathrm{H}-1 ")^{13} \mathrm{C}$ NMR $\left(\mathrm{CD}_{3} \mathrm{OD}, 126 \mathrm{MHz}\right) \delta 13.6$ (C-19), 16.2 (C-21), 16.6 (C-27), 17.0 (C18), 17.7 (C-6"), 18.2 (C-6'), 21.8 (C-11), 31.6 (C-25), 31.8 (C-2), 32.5 (C-4), 34.5 (C-15), 34.9 (C-8), 38.2 (C-1), 38.3 (C-24), 41.0 (C-12), 41.5 (C-7),43.6(C-20), 51.6 (C-5), 54.9 (C-9), 56.5 (C-14), 64.1 (C-17), 69.3 (C-26), 69.9 (C-5"), 70.6 (C-23), 71.7 (C-3), 72.1 (C-3"), 72.2 (C-2"), 72.8 (C-5'), 73.9 (C-4"), 75.5 (C-4'), 76.2 (C-2'), 80.2 (C-6), 84.2 (C-3'), 85.2 (C-16), 102.6 (C1"), 104.9 (C-1'). ESI-HRMS m/z 741.4446 [M+H]+ (calculated for C39H65O13, 741.4425, $\Delta \mathrm{ppm}=2.8)$.

Compound 3, Torvoside K. ${ }^{1} \mathrm{H}$ NMR $\left(\mathrm{CD}_{3} \mathrm{OD}, 500 \mathrm{MHz}\right) \delta 0.69(1 \mathrm{H}, \mathrm{m}, \mathrm{H}-9), 0.82$ (3H, s, Me-18), 0.87 (3H, s, Me-19), 0.95 (1H, m, H-7b), 1.02 (1H, m, H-1b), 1.12 (3H, d, J=7.0 Hz, Me-21), 1.14 (2H, m, H-4b, H-12b), 1.16 (1H, m, H-5), 1.17 (1H, m, H-14), 1.21 (3H, d, J=7.3 Hz, Me-27), 1.24 (3H, d, J=6.2 Hz, Me-6"), 1.27 (1H, m, H-15b), 1.28 (3H, d, J=6.1 Hz, Me-6'), 1.32 (1H, m, H-11b), 1.40 (1H, m, H-2b), 1.52 (1H, m, H-24b), 1.55 (1H, m, H-11a), 1.65 (1H, 
m , H-8), 1.67 (1H, m, H-25), 1.70 (1H, m, H-17), 1.71 (1H, m, H-1a), 1.75 (2H, m, H-2a, H12a), 1.96 (1H, m, H-15a), 2.06 (1H, m, H-24a), 2.17 (1H, m, H-7a), 2.35 (1H, m, H-20), 2.38 $(1 \mathrm{H}, \mathrm{m}, \mathrm{H}-4 \mathrm{a}), 3.01\left(1 \mathrm{H}, \mathrm{t}, J=9.0 \mathrm{~Hz}, \mathrm{H}-4{ }^{\prime}\right), 3.26(1 \mathrm{H}, \mathrm{dd}, J=9.0,7.9 \mathrm{~Hz}, \mathrm{H}-2)^{\prime}, 3.31$ (2H, m, H26b, H-5'), 3.39 (2H, m, H-6, H-4"), 3.42 (1H, t, J=9.0 Hz, H-3'), 3.45 (1H, m, H-3), 3.57 (1H, t, $J=3.9 \mathrm{~Hz}, \mathrm{H}-23), 3.69$ (1H, dd, $J=9.5,3.4 \mathrm{~Hz}, \mathrm{H}-3 "), 3.93$ (1H, dd, J=3.4, $1.7 \mathrm{~Hz}, \mathrm{H}-2 "), 3.96$ (1H, dd, J=11.2, 3.8 Hz, H-26a), 3.99 (1H, dq, J=9.5, 6.2 Hz, H-5"), 4.27 (1H, d, J=7.9 Hz, H1'), 4.47 (1H, q, $J=7.8 \mathrm{~Hz}, \mathrm{H}-16), 5.14(1 \mathrm{H}, \mathrm{d}, J=1.7 \mathrm{~Hz}, \mathrm{H}-1 ")^{13} \mathrm{C}$ NMR $\left(\mathrm{CD}_{3} \mathrm{OD}, 126 \mathrm{MHz}\right) \delta$ 13.6 (C-19), 16.6 (C-18), 16.7 (C-21), 17.7 (C-6"), 18.1 (C-6'), 20.0 (C-27), 21.9 (C-11), 27.7 (C-25), 31.6 (C-2), 32.4 (C-4), 32.7 (C-15), 34.3 (C-24), 35.0 (C-8), 38.3 (C-1), 40.7 (C-12), 40.8 (C-20), 41.5 (C-7), 51.6 (C-5), 54.9 (C-9), 57.3 (C-14), 65.2 (C-17), 66.0 (C-26), 69.8 (C5"), 71.0 (C-23), 71.6 (C-3), 72.0 (C-3"), 72.2 (C-2"), 72.8 (C-5'), 73.9 (C-4"), 75.5 (C-4'), 76.2 (C-2'), 80.2 (C-6), 82.4 (C-16), 84.0 (C-3'), 102.7 (C-1"), 105.0 (C-1'). ESI-HRMS m/z 741.4453 $[\mathrm{M}+\mathrm{H}]+($ calculated for $\mathrm{C} 39 \mathrm{H} 65 \mathrm{O} 13,741.4425, \Delta \mathrm{ppm}=3.8)$.

Compound 4, Paniculonin B. ${ }^{1} \mathrm{H}$ NMR $\left(\mathrm{CD}_{3} \mathrm{OD}, 500 \mathrm{MHz}\right) \delta 0.69(1 \mathrm{H}, \mathrm{td}, J=12.0,3.9 \mathrm{~Hz}, \mathrm{H}-$ 9), 0.86 (3H, s, Me-18), 0.88 (3H, s, Me-19), 0.95 (1H, m, H-7b), 0.96 (3H, d, J=7.0 Hz, Me-21), 1.03 (1H, m, H-1b), 1.11 (3H, d, J=6.8 Hz, Me-27), 1.14 (1H, m, H-4b), 1.16 (1H, m, H-5), 1.17 (1H, m, H-12b), 1.18 (1H, m, H-14), 1.24 (3H, d, J=6.2 Hz, Me-6"), 1.27 (3H, d, J=6.1 Hz, Me6'), 1.33 (1H, m, H-11b), 1.41 (2H, m, H-2b, H-15b), 1.55 (1H, brd, J=13.6 Hz, H-11a), 1.67 (2H, m, H-8, H-24b), 1.71 (1H, m, H-1a), 1.75 (2H, m, H-2a, H-12a), 1.76 (1H, m, H-17), 1.89 (1H, m, H-25), 1.90 (1H, m, H-24a), 1.96 (1H, m, H-15a), 2.18 (1H, dt, J=12.5, 4.0 Hz, H-7a), 2.38 (1H, m, H-4a), 2.53 (1H, p, J=7.0 Hz, H-20), 3.01 (1H, t, J=9.0 Hz, H-4'), 3.19 (1H, d, $J=11.0 \mathrm{~Hz}, \mathrm{H}-26 \mathrm{~b}), 3.26$ (1H, dd, $\left.J=9.0,7.9 \mathrm{~Hz}, \mathrm{H}-2^{\prime}\right), 3.31$ (1H, m, H-5'), 3.39 (1H, t, $J=9.5 \mathrm{~Hz}$, H-4"), 3.39 (1H, m, H-6), 3.42 (1H, t, J=9.0 Hz, H-3'), 3.45 (1H, m, H-3), 3.67 (1H, dd, J=11.3, $5.0 \mathrm{~Hz}, \mathrm{H}-23), 3.69$ (1H, dd, J=9.5, 3.3 Hz, H-3"), 3.85 (1H, dd, J=11.0, 2.4 Hz, H-26a), 3.93 (1H, dd, J=3.3, $\left.1.8 \mathrm{~Hz}, \mathrm{H}-2^{\prime \prime}\right), 3.99$ (1H, dq, J=9.5, $\left.6.2 \mathrm{~Hz}, \mathrm{H}-5 "\right), 4.27$ (1H, d, J=7.9 Hz, H-1'), $4.44(1 \mathrm{H}, \mathrm{q}, J=7.5 \mathrm{~Hz}, \mathrm{H}-16), 5.14(1 \mathrm{H}, \mathrm{d}, J=1.8 \mathrm{~Hz}, \mathrm{H}-1 ") .{ }^{13} \mathrm{C} \mathrm{NMR}\left(\mathrm{CD}_{3} \mathrm{OD}, 126 \mathrm{MHz}\right) \delta$ 13.8 (C-19), 14.3 (C-21), 17.0 (C-18), 17.6 (C-27), 17.9 (C-6"), 18.4 (C-6'), 22.1 (C-11), 31.3 (C-25), 31.9 (C-2), 32.6 (C-15), 32.7 (C-4), 35.1 (C-8), 36.0 (C-24), 37.0 (C-20), 37.6 (C-10), 38.5 (C-1), 41.3 (C-12), 41.7 (C-7), 42.2 (C-13), 51.8 (C-5), 55.1 (C-9), 57.4 (C-14), 63.2 (C17), 64.0 (C-23), 65.0 (C-26), 70.0 (C-5"), 71.9 (C-3), 72.3 (C-3"), 72.4 (C-2"), 73.0 (C-5'), 74.0 (C-4"), 75.7 (C-4'), 76.4 (C-2'), 80.4 (C-6), 82.6 (C-16), 84.3 (C-3'), 102.8 (C-1"), 105.1 (C-1'), 112.6 (C-22). ESI-HRMS m/z 741.4438 [M+H $]^{+}$(calculated for C39H65O13, 741.4425, $\Delta \mathrm{ppm}=$ $1.8)$. 
Compound 5, (22R,23S,25S)-3 $\beta, 6 \alpha, 23-t$ trihydroxy-5 $\alpha$-spirostane6-O- $\beta$-D-xylopyranosyl$\left(\mathbf{1} \rightarrow\right.$ 3)-O- $\beta$-D-quinovopyranoside. ${ }^{1} \mathrm{H}$ NMR $\left(\mathrm{CD}_{3} \mathrm{OD}, 500 \mathrm{MHz}\right) \delta 0.69(1 \mathrm{H}, \mathrm{td}, J=11.5,4.2 \mathrm{~Hz}$, H-9), 0.77 (3H, d, J=6.6 Hz, Me-27), 0.81 (3H, s, Me-18), 0.87 (3H, s, Me-19), 0.97 (1H, m, H7b), 1.03 (1H, m, H-1b), 1.09 (3H, d, J=7.0 Hz, Me-21), 1.14 (2H, m, H-4b, H-12b), 1.16 (1H, m, H-5), 1.18 (1H, m, H-14), 1.27 (3H, d, J=6.0 Hz, Me-6'), 1.27 (1H, m, H-15b), 1.32 (1H, m, H-11b), 1.41 (1H, m, H-2b), 1.55 (1H, m, H-11a), 1.61 (1H, m, H-24b), 1.65 (1H, m, H-8), 1.67 (1H, m, H-24a), 1.69 (1H, m, H-17), 1.71 (1H, m, H-1a), 1.75 (2H, m, H-2a, H-12a), 1.98 (1H, m, H-15a), 2.05 (1H, m, H-25), 2.16 (1H, dt, J=12.4, 4.2 Hz, H-7a), 2.25 (1H, p, J=7.0 Hz, H20), 2.40 (1H, dd, $J=10.4,4.2 \mathrm{~Hz}, \mathrm{H}-4 \mathrm{a}), 3.05$ (1H, t, $J=9.1 \mathrm{~Hz}, \mathrm{H}-4$ '), 3.23 (1H, t, $J=11.1 \mathrm{~Hz}, \mathrm{H}-$ 5"b), 3.26 (1H, dd, J=9.2, 7.5 Hz, H-2"), 3.32 (1H, m, H-5'), 3.33 (1H, m, H-3"), 3.35 (1H, m, H2'), 3.36 (1H, t, J=11.6 Hz, H-26b), 3.40 (1H, m, H-6), 3.43 (1H, t, J=9.1 Hz, H-3'), 3.46 (2H, m, H-3, H-26a), 3.49 (1H, m, H-4"), 3.52 (1H, t, J=2.8 Hz, H-23), 3.90 (1H, dd, J=11.1, 5.4 Hz, H5"a), 4.32 (1H, d, J=7.8 Hz, H-1'), 4.45 (1H, td, J=7.7, 5.5 Hz, H-16), 4.48 (1H, d, J=7.5 Hz, H1 1"). ${ }^{13} \mathrm{C}$ NMR (CD $\left.3 \mathrm{OD}, 126 \mathrm{MHz}\right) \delta 13.8$ (C-19), 16.7 (C-18), 17.0 (C-21), 17.4 (C-27), 18.2 (C6'), 22.0 (C-11), 25.0 (C-25), 31.9 (C-2), 32.7 (C-4), 33.0 (C-15), 35.3 (C-8), 37.6 (C-10, C-24), 38.5 (C-1), 40.7 (C-12), 41.6 (C-7), 41.7 (C-20), 42.1 (C-13), 51.8 (C-5), 55.1 (C-9), 57.5 (C14), 65.7 (C-17), 67.1 (C-5"), 67.5 (C-26), 71.0 (C-4"), 71.1 (C-23), 71.8 (C-3), 72.7 (C-5'), 75.2 (C-2'), 75.3 (C-4', C-2"), 77.7 (C-3"), 80.3 (C-6), 82.4 (C-16), 87.7 (C-3'), 104.8 (C-1'), 106.0 (C1"), 110.0 (C-22). ESI-HRMS m/z $727.4292[\mathrm{M}+\mathrm{H}]^{+}$(calculated for $\mathrm{C}_{38} \mathrm{H}_{63} \mathrm{O}_{13}, 727.4269, \Delta \mathrm{ppm}$ $=3.2)$.

Compound 6, Paniculonin A. ${ }^{1} \mathrm{H}$ NMR $\left(\mathrm{CD}_{3} \mathrm{OD}, 500 \mathrm{MHz}\right) \delta 0.70(1 \mathrm{H}, \mathrm{td}, J=11.4,3.7 \mathrm{~Hz}, \mathrm{H}-9)$, 0.86 (3H, s, Me-18), 0.88 (3H, s, Me-19), 0.96 (1H, m, H-7b), 0.96 (3H, d, J=7.0 Hz, Me-21), $1.03(1 \mathrm{H}, \mathrm{t}, J=14.3 \mathrm{~Hz}, \mathrm{H}-1 \mathrm{~b}), 1.11(3 \mathrm{H}, \mathrm{d}, J=6.7 \mathrm{~Hz}, \mathrm{Me}-27), 1.14(1 \mathrm{H}, \mathrm{m}, \mathrm{H}-4 \mathrm{~b}), 1.17$ (2H, m, H-5, H-12b), 1.19 (1H, m, H-14), 1.27 (3H, d, J=6.1 Hz, Me-6'), 1.33 (1H, m, H-11b), 1.40 (1H, m, H-15b), 1.41 (1H, m, H-2b), 1.55 (1H, brd, J=13.7 Hz, H-11a), 1.68 (2H, m, H-8, H-24b), 1.72 (1H, m, H-1a), 1.75 (1H, m, H-12a), 1.76 (2H, m, H-2a, H-17), 1.89 (1H, m, H-25), 1.90 (1H, m, H-24a), 1.95 (1H, m, H-15a), 2.17 (1H, dt, J=12.6, 4.4 Hz, H-7a), 2.40 (1H, brd, J=11.3 Hz, H-4a), 2.53 (1H, p, J=7.0 Hz, H-20), 3.05 (1H, t, J=9.0 Hz, H-4'), 3.19 (1H, d, J=11.4 Hz, H26b), 3.23 (1H, t, J=11.2 Hz, H-5"b), 3.26 (1H, dd, J=9.1, 7.6 Hz, H-2"), 3.31 (1H, m, H-5'), 3.32 (1H, m, H-3"), 3.34 (1H, m, H-2'), 3.40 (1H, m, H-6), 3.43 (1H, t, J=9.0 Hz, H-3'), 3.46 (1H, m, H-3), 3.50 (1H, m, H-4"), 3.66 (1H, dd, J=10.3, 5.2 Hz, H-23), 3.85 (1H, d, J=11.0 Hz, H-26a), 
3.90 (1H, dd, $J=11.2,5.4 \mathrm{~Hz}, \mathrm{H}-5 " \mathrm{a}), 4.32$ (1H, d, $J=7.8 \mathrm{~Hz}, \mathrm{H}-1$ '), 4.44 (1H, q, $J=7.4$ Hz, H-16), $4.48(1 \mathrm{H}, \mathrm{d}, J=7.6 \mathrm{~Hz}, \mathrm{H}-1 ") .{ }^{13} \mathrm{C}$ NMR $\left(\mathrm{CD}_{3} \mathrm{OD}, 126 \mathrm{MHz}\right) \delta 13.3$ (C-19), 13.8 (C-21), 16.5 (C18), 17.1 (C-27), 17.7 (C-6'), 21.6 (C-11), 30.9 (C-25), 31.4 (C-2), 32.0 (C-15), 32.1 (C-4), 34.5 (C-8), 35.5 (C-24), 36.6 (C-20), 37.2 (C-10), 37.9 (C-1), 40.8 (C-12), 41.2 (C-7), 42.0 (C-13), 51.2 (C-5), 54.6 (C-9), 56.9 (C-14), 62.6 (C-17), 63.5 (C-23), 64.7 (C-26), 66.5 (C-5"), 70.6 (C4"), 71.3 (C-3), 72.3 (C-5'), 74.6 (C-2'), 74.8 (C-2"), 74.9 (C-4'), 77.1 (C-3"), 79.7 (C-6), 82.1 (C16), 87.2 (C-3'), 104.3 (C-1'), 105.5 (C-1"), 112.0 (C-22). ESI-HRMS m/z $727.4302[\mathrm{M}+\mathrm{H}]^{+}$ (calculated for $\mathrm{C}_{38} \mathrm{H}_{63} \mathrm{O}_{13}, 727.4269, \Delta \mathrm{ppm}=4.5$ )

\section{Aglycone 7a/7b}

Solanolide 7a. ${ }^{1} \mathrm{H}$ NMR ( $\left.\mathrm{CD}_{3} \mathrm{OD}, 500 \mathrm{MHz}\right) \delta 0.73$ (1H, m, H-9), 0.73 (3H, s, Me-18), 0.85 (3H, s, Me-19), 0.95 (1H, m, H-7b), 1.03 (2H, m, H-1b, H-5), 1.17 (2H, m, H-4b, H-12b), 1.21 (1H, m, H-14), 1.28 (3H, d, J=8.0 Hz, Me-21), 1.36 (1H, m, H-11b), 1.41 (1H, m, H-2b), 1.47 (1H, m, H-15b), 1.58 (1H, m, H-11a), 1.63 (1H, m, H-8), 1.72 (1H, m, H-1a), 1.76 (1H, m, H-2a), 1.81 (1H, m, H-12a), 1.97 (1H, m, H-7a), 1.98 (1H, m, H-17), 2.18 (1H, m, H-4a), 2.30 (1H, m, H15a), 2.61 (1H, m, H-20), 3.34 (1H, m, H-6), 3.49 (1H, m, H-3), 5.03 (1H, td, J=7.8, 4.6 Hz, H16). ${ }^{13} \mathrm{C}$ NMR $\left(\mathrm{CD}_{3} \mathrm{OD}, 126 \mathrm{MHz}\right) \delta 13.6$ (C-19), 13.9 (C-18), 17.9 (C-21), 21.4 (C-11), 31.6 (C-2), 32.8 (C-4), 33.8 (C-15), 34.7 (C-8), 37.4 (C-20), 37.6 (C-10), 38.3 (C-1), 38.7 (C-12), 42.2 (C-13), 42.3 (C-7), 52.6 (C-5), 54.9 (C-9), 55.4 (C-14), 59.9 (C-17), 69.6 (C-6), 71.7 (C-3), $84.6(\mathrm{C}-16), 183.9(\mathrm{C}-22)$. ESI-HRMS m/z $363.2530[\mathrm{M}+\mathrm{H}]^{+}$(calculated for $\mathrm{C}_{22} \mathrm{H}_{3543}, 363.2535, \Delta \mathrm{ppm}=$ 1.4).

Solanolide-20-epimer 7b. ${ }^{1} \mathrm{H}$ NMR $\left(\mathrm{CD}_{3} \mathrm{OD}, 500 \mathrm{MHz}\right) \delta 0.73(1 \mathrm{H}, \mathrm{m}, \mathrm{H}-9), 0.81$ (3H, s, Me18), 0.85 (3H, s, Me-19), 0.95 (1H, m, H-7b), 1.03 (2H, m, H-1b, H-5), 1.17 (2H, m, H-4b, H12b), 1.21 (1H, m, H-14), 1.30 (3H, d, J=8.1 Hz, Me-21), 1.36 (1H, m, H-11b), 1.41 (1H, m, H2b), 1.47 (1H, m, H-15b), 1.58 (1H, m, H-11a), 1.63 (1H, m, H-8), 1.72 (1H, m, H-1a), 1.76 (1H, m, H-2a), 1.81 (1H, m, H-12a), 1.97 (1H, m, H-7a), 2.18 (1H, m, H-4a), 2.30 (1H, m, H-15a), $2.31(1 \mathrm{H}, \mathrm{m}, \mathrm{H}-17), 2.97$ (1H, m, H-20), 3.34 (1H, m, H-6), 3.49 (1H, m, H-3), 4.83 (1H, td, $J=7.3,3.7 \mathrm{~Hz}, \mathrm{H}-16) .{ }^{13} \mathrm{C}$ NMR $\left(\mathrm{CD}_{3} \mathrm{OD}, 126 \mathrm{MHz}\right) \delta 10.3$ (C-21), 13.5 (C-19), 14.0 (C-18), 21.4 (C-11), 31.6 (C-2), 32.8 (C-4), 33.8 (C-15), 34.7 (C-8), 37.6 (C-10), 38.3 (C-1), 38.7 (C20), 38.7 (C-12), 42.2 (C-13), 42.3 (C-7), 52.6 (C-5), 54.9 (C-9), 55.4 (C-14), 56.6 (C-17), 69.6 (C-6), 71.7 (C-3), 84.1 (C-16), 182.2 (C-22). ESI-HRMS m/z $363.2522[\mathrm{M}+\mathrm{H}]^{+}$(calculated for $\mathrm{C}_{22} \mathrm{H}_{3543}$, $363.2535, \Delta \mathrm{ppm}=3.6)$. 


\section{Animals}

Zebrafish. Adult zebrafish (AB strain) were reared at $28^{\circ} \mathrm{C}$ on a $14 / 10$-hour light/dark cycle according to standard aquaculture conditions. Eggs were collected following natural spawning, sorted and raised in 0.3x Danieau's solution (1.5 mM HEPES, pH 7.6, $17.4 \mathrm{mM} \mathrm{NaCl}, 0.21 \mathrm{mM}$ $\mathrm{KCl}, 0.12 \mathrm{mM} \mathrm{MgSO}_{4}$, and $\left.0.18 \mathrm{mM} \mathrm{Ca}\left(\mathrm{NO}_{3}\right)_{2}\right)$ under constant light conditions in an incubator set at $28^{\circ} \mathrm{C}$ until 6 or $7 \mathrm{dpf}$. All zebrafish experiments carried out were approved by the Ethics Committee of the University of Leuven.

\section{Evaluation of anticonvulsant activity}

Automated larval zebrafish-PTZ assay. One 7-dpf zebrafish larva was placed per well in a 96well plate. Excess larval medium was removed and replaced with $100 \mu \mathrm{L}$ of either control or sample solution. The prepared plate was placed in a dark box inside an incubator, set at $28^{\circ} \mathrm{C}$, for 1 or 18 hours, and subsequently inspected per well for signs of toxicity (e.g., irregular heart-rate, loss of posture, edema, necrosis, delayed startle or touch response). The maximum tolerated concentration (MTC) was designated as the highest sample concentration that did not elicit any signs of toxicity in 6/7-dpf larvae after 18 hours of exposure (Afrikanova, 2013). Upon addition of $100 \mu \mathrm{L}$ of $40 \mathrm{mM}$ PTZ per well, the plate was positioned in the zebrafish tracking box (Viewpoint, Lyon, France), and the larvae allowed to habituate for 5 minutes before recording for 30 minutes, with movement values determined at 5 minute intervals. Tracking data was exported into Excel format and processed as such before statistical analysis via GraphPad ${ }^{\mathrm{TM}}$ Prism v.5 for Windows. Each tracking data set was normalized against the PTZ-only control values (set at $100 \%$ ) within each set, with each subsequent replicate set pooled before two-way ANOVA with Bonferroni post hoc analysis. 


\section{Xenopus laevis $\mathrm{GABA}_{\mathrm{A}}$ receptor overexpression system}

Oocyte preparation and injection. The use of animals and all experimental procedures were approved by local authorities (Regierungspraesidium Tuebingen, Tuebingen, Germany). Oocytes were obtained from the Institute of Physiology I, Tübingen. Preparation of oocytes for recordings included treatment with collagenase $(1 \mathrm{mg} / \mathrm{ml}$ of type CLS II collagenase, Biochrom KG, Berlin, Germany) in OR2 solution (mM: $82.5 \mathrm{NaCl}, 2.5 \mathrm{KCl}, 1 \mathrm{MgCl}_{2}$ and $5 \mathrm{HEPES}, \mathrm{pH}$ 7.6), followed by thorough washing and storing at $16{ }^{\circ} \mathrm{C}$ in Barth solution (mM:88 NaCl, $2.4 \mathrm{NaHCO}_{3}, 1 \mathrm{KCl}$, $0.33 \mathrm{Ca}\left(\mathrm{NO}_{3}\right)_{2}, 0.41 \mathrm{CaCl}_{2}, 0.82 \mathrm{MgSO}_{4}$ and 5 Tris/ $\mathrm{HCl}, \mathrm{pH} 7.4$ with $\left.\mathrm{NaOH}\right)$ supplemented with $50 \mathrm{Lg} / \mathrm{ml}$ gentamicin (Biochrom KG, Germany). For injection and recording oocytes were plated in 96 well plates. All cRNA concentrations were adjusted to $800 \mathrm{ng} / \mathrm{subunit}$ and $70 \mathrm{nl}$ of the $\alpha 1 \beta 2 \gamma 2 \mathrm{~s}$ cRNA mixed in a 1:1:2 ratio were injected in each oocyte using robooinject ${ }^{\circledR}$ (Multi Channel Systems, Reutlingen, Germany). Recordings were done at day 3 after injection. Amplitudes of interest for all currents recorded from the same oocyte were normalized to the first GABA pulse.

Automated oocyte two-microelectrode voltage clamp. The currents in oocytes were recorded at room temperature $\left(20-22^{\circ} \mathrm{C}\right)$ using roboocyte2 ${ }^{\circledR}$ (Multi Channel Systems, Reutlingen, Germany). Prepulled and prepositioned intracellular glass microelectrodes had a resistance of 0.3-1 MO when filled with $1 \mathrm{M} \mathrm{KCl} / 1.5 \mathrm{M} \mathrm{KAc}$. The bath solution was ND96 (im mM: 93.5 $\mathrm{NaCl}, 2 \mathrm{KCl}, 1.8 \mathrm{CaCl} 2,2 \mathrm{MgCl} 2$ and $5 \mathrm{Hepes} ; \mathrm{pH} 7.5)$. All compounds were applied for $15 \mathrm{sec}$ followed by 5 minutes washout with ND96. 


\section{Acknowledgements}

OEB is a recipient of a $\mathrm{PhD}$ fellowship from the IRO (Interfacultaire Raad voor Ontwikkelingssamenwerking) program of KU Leuven. 


\section{References}

Abdullah, J.M., Zhang, J., 2013. The GABA A receptor subunits heterologously expressed in Xenopus oocytes. Mini Rev Med Chem 13, 744-748.

Arif, H., Buchsbaum, R., Weintraub, D., Pierro, J., Resor, S.R., Hirsch, L.J., 2009. Patient-reported cognitive side effects of antiepileptic drugs: Predictors and comparison of all commonly used antiepileptic drugs. Epilepsy \& Behavior 14, 202-209.

Arroyo, S., de la Morena, A., 2001. Life-threatening adverse events of antiepileptic drugs. Epilepsy Res 47, 155-174.

Bohni, N., Cordero-Maldonado, M.L., Maes, J., Siverio-Mota, D., Marcourt, L., Munck, S., Kamuhabwa, A.R., Moshi, M.J., Esguerra, C.V., de Witte, P.A., Crawford, A.D., Wolfender, J.L., 2013. Integration of Microfractionation, qNMR and zebrafish screening for the in vivo bioassay-guided isolation and quantitative bioactivity analysis of natural products. PloS one 8 , e64006.

Buenafe, O.E., Orellana-Paucar, A., Maes, J., Huang, H., Ying, X., De Borggraeve, W., Crawford, A.D., Luyten, W., Esguerra, C.V., de Witte, P., 2013. Tanshinone IIA Exhibits Anticonvulsant Activity in Zebrafish and Mouse Seizure Models. ACS chemical neuroscience 4, 1479-1487.

Carpay, J.A., Aldenkamp, A.P., van Donselaar, C.A., 2005. Complaints associated with the use of antiepileptic drugs: results from a community-based study. Seizure-Eur J Epilep 14, 198-206.

Chauhan, K., Sheth, N., Ranpariya, V., Parmar, S., 2011. Anticonvulsant activity of solasodine isolated from Solanum sisymbriifolium fruits in rodents. Pharm Biol 49, 194-199.

Colmenares, A.P., Rojas, L.B., Mitaine-Offer, A.C., Pouysegu, L., Quideau, S., Miyamoto, T., Tanaka, C., Paululat, T., Usubillaga, A., Lacaille-Dubois, M.A., 2013. Steroidal saponins from the fruits of Solanum torvum. Phytochemistry 86, 137-143.

Eugster, P.J., Guillarme, D., Rudaz, S., Veuthey, J.L., Carrupt, P.A., Wolfender, J.L., 2011. Ultra high pressure liquid chromatography for crude plant extract profiling. J AOAC Int 94, 51-70.

Galanopoulou, A.S., Kokaia, M., Loeb, J.A., Nehlig, A., Pitkanen, A., Rogawski, M.A., Staley, K.J., Whittemore, V.H., Dudek, F.E., 2013. Epilepsy therapy development: Technical and methodologic issues in studies with animal models. Epilepsia 54, 13-23.

Kesselmeier, J., Budzikiewicz, H., 1979. Identification of saponins as structural building units in isolated prolamellar bodies from etioplasts of Avena sativa L. Z Pflanzenphysiol 91, 333-344.

Lee, C.L., Hwang, T.L., He, W.J., Tsai, Y.H., Yen, C.T., Yen, H.F., Chen, C.J., Chang, W.Y., Wu, Y.C., 2013. Anti-neutrophilic inflammatory steroidal glycosides from Solanum torvum. Phytochemistry 95, 315-321.

Lu, Y.Y., Luo, J.G., Huang, X.F., Kong, L.Y., 2009. Four new steroidal glycosides from Solanum torvum and their cytotoxic activities. Steroids 74, 95-101.

Moshi, M.J., Kagashe, G.A., Mbwambo, Z.H., 2005. Plants used to treat epilepsy by Tanzanian traditional healers. J Ethnopharmacol 97, 327-336.

Nafady, A.M., El-Shanawany, M.A., Mohamed, M.F., Hassanean, H.A.H., Zhu, X.H., Yoshihara, T., Okawa, M., Ikeda, T., Nohara, T., 2003. Peculiar side-chain fission of steroidal glycosides. Tetrahedron Lett 44, 3509-3511. 
Orellana-Paucar, A.M., Serruys, A.S., Afrikanova, T., Maes, J., De Borggraeve, W., Alen, J., Leon-Tamariz, F., Wilches-Arizabala, I.M., Crawford, A.D., de Witte, P.A., Esguerra, C.V., 2012. Anticonvulsant activity of bisabolene sesquiterpenoids of Curcuma longa in zebrafish and mouse seizure models. Epilepsy \& behavior : E\&B 24, 14-22.

Perucca, E., 1998. Pharmacoresistance in epilepsy - How should it be defined? Cns Drugs 10, 171-179.

Quisumbing, E., 1951. Medicinal plants of the Philippines. Bureau of Printing,, Manila.

Schmidt, D., 2009. Drug treatment of epilepsy: options and limitations. Epilepsy \& behavior : E\&B 15, 5665.

Schmidt, D., Rogawski, M.A., 2002. New strategies for the identification of drugs to prevent the development or progression of epilepsy. Epilepsy Res 50, 71-78.

Shu, W., Wu, C., Zhang, Y., Ye, W.C., Zhou, G., 2013. Two new steroidal glycosides isolated from the aerial part of Solanum torvum Swartz. Nat Prod Res 27, 1982-1986.

Thurman, D.J., Beghi, E., Begley, C.E., Berg, A.T., Buchhalter, J.R., Ding, D., Hesdorffer, D.C., Hauser, W.A., Kazis, L., Kobau, R., Kroner, B., Labiner, D., Liow, K., Logroscino, G., Medina, M.T., Newton, C.R., Parko, K., Paschal, A., Preux, P.M., Sander, J.W., Selassie, A., Theodore, W., Tomson, T., Wiebe, S., Epidemiology, I.C.o., 2011. Standards for epidemiologic studies and surveillance of epilepsy. Epilepsia 52 Suppl 7, 2-26.

Wolfender, J.L., Queiroz, E.F., 2012. New approaches for studying the chemical diversity of natural resources and the bioactivity of their constituents. Chimia 66, 324-329.

Yu, K., Chen, F., Li, C., 2012. Absorption, Disposition, and Pharmacokinetics of Saponins from Chinese Medicinal Herbs: What Do We Know and What Do We Need to Know More? Curr Drug Metab 13, $577-$ 598.

Zhu, Z.Y., Gao, L., Wang, J.K., 2003. Illustrated Handbook for Medicinal Materials from Nature in Yunnan. Yunnan Science and Technology Press, Kunming. 
Figure 1. (A-C) PTZ-induced activity curve for a 30-minute tracking period of 7-dpf zebrafish larvae after 18-hour pre-treatment with different concentrations of (A) S. torvum aqueous extract (from serial extractions of increasing polarity), (B) S. torvum methanol crude extract, (C) $S$. torvum decoction. (D) Total movement after 30-minute tracking period (expressed in \%activity) of A-C, represented in a bar graph. All results were normalized against PTZ controls (set at $100 \%)$. Analysis of the activity curves was done by two-way ANOVA, with P values $<0.05\left(^{*}\right)$, $<0.01(* *)$ and $<0.001(* * *)$ indicated per 5-minute time slice. For the bar graph, statistical analysis was done by one-way ANOVA with Dunnett's Test to assess the samples vs. PTZ-only controls, with $\mathrm{P}$ values $<0.05(*),<0.01(* *)$ and $<0.001(* * *)$.

Figure 2. UHPLC-TOF-MS analysis of the methanolic and water extracts of S. torvum.

Figure 3. A) HPLC-microfractionation of the methanolic extract of S. torvum. B) Active zone contain antiepileptic compounds. C) MS spectra of the main compounds present in the active zone.

Figure 4. Isolated compounds from the methanolic extract of $S$. torvum, the common aglycone obtained by acid hydrolysis of the extract, and the structure of the ganaxolone.

Figure 5. PTZ-induced activity curve for a 30-minute tracking period of 7-dpf zebrafish larvae after 18-hour pre-treatment with different concentrations of compounds 1-6 (number labels on each graph correspond to compound). Total movement after 30-minute tracking period (expressed in \%activity) represented in a bar graph (7) below. All results were normalized against PTZ controls (set at 100\%). Analysis of the activity curves was done by two-way ANOVA, with $\mathrm{P}$ values $<0.05(*),<0.01(* *)$ and $<0.001(* * *)$ indicated per time period. For the bar graph, statistical analysis was done by one-way ANOVA with Dunnett's Test to assess the samples vs. PTZ-only controls, with P values $<0.05(*),<0.01(* *)$ and $<0.001$ (***). 
Figure 6. PTZ-induced activity curve for a 30-minute tracking period of 7-dpf zebrafish larvae after 18-hour pre-treatment with different concentrations of (A) compound 7 (solanolide), and (B) 8 (ganaxolone). All results were normalized against PTZ controls (set at 100\%). Analysis was done by two-way ANOVA, with $\mathrm{P}$ values $<0.05(*),<0.01(* *)$ and $<0.001(* * *)$ indicated per time period.

Figure 7. (A) Representative current traces generated in response to $1 \mathrm{mM}$ GABA or $10 \mu \mathrm{M}$ of indicated compounds applied for 15 seconds on Xenopus laevis oocytes expressing $\alpha 1 \beta 2 \gamma 2 \mathrm{~s}$ receptors. (B) Responses to application of indicated compounds normalized to $1 \mathrm{mM}$ GABA applied at the beginning of each recording; $n=4-6$. (C) Responses to compounds applied together with $10 \mu \mathrm{M}$ GABA in $10 \mu \mathrm{M}$ or $100 \mu \mathrm{M}$ concentrations and normalized to the response to $10 \mu \mathrm{M}$ GABA applied at the beginning of each recording. Washing time between applications was 5 $\min ; n=4$ 
Figure 1

A
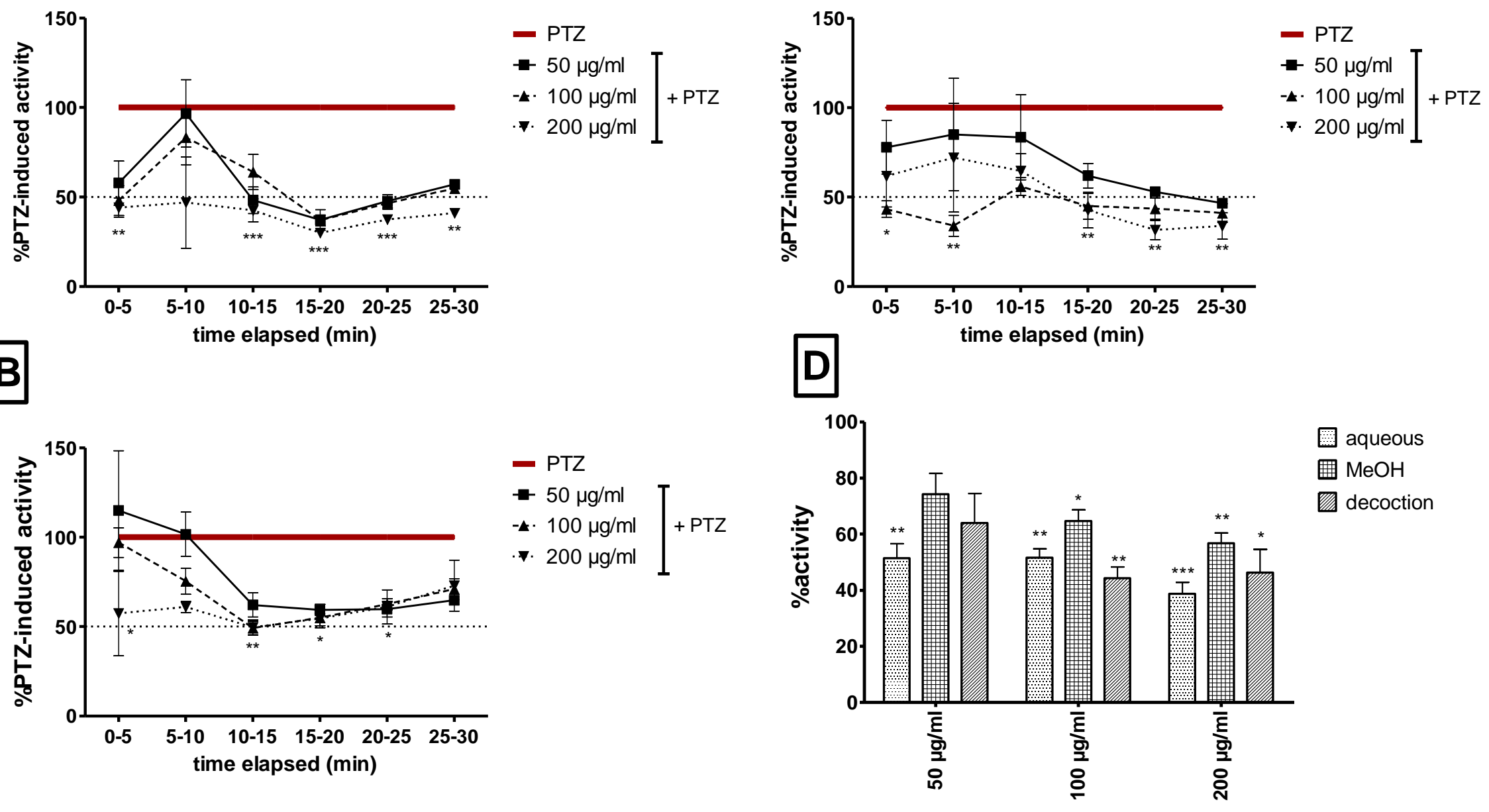
Figure 2

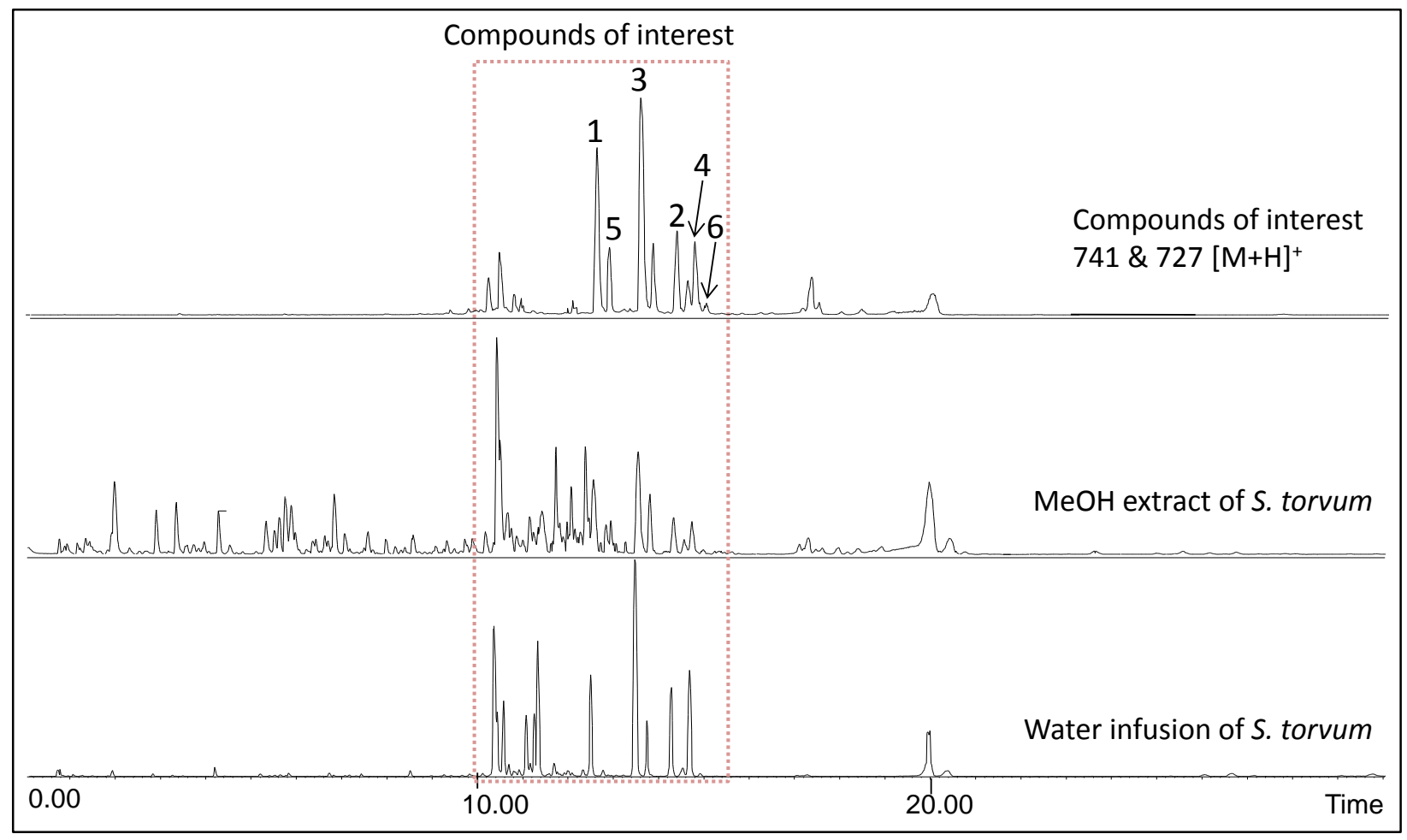


Figure 3
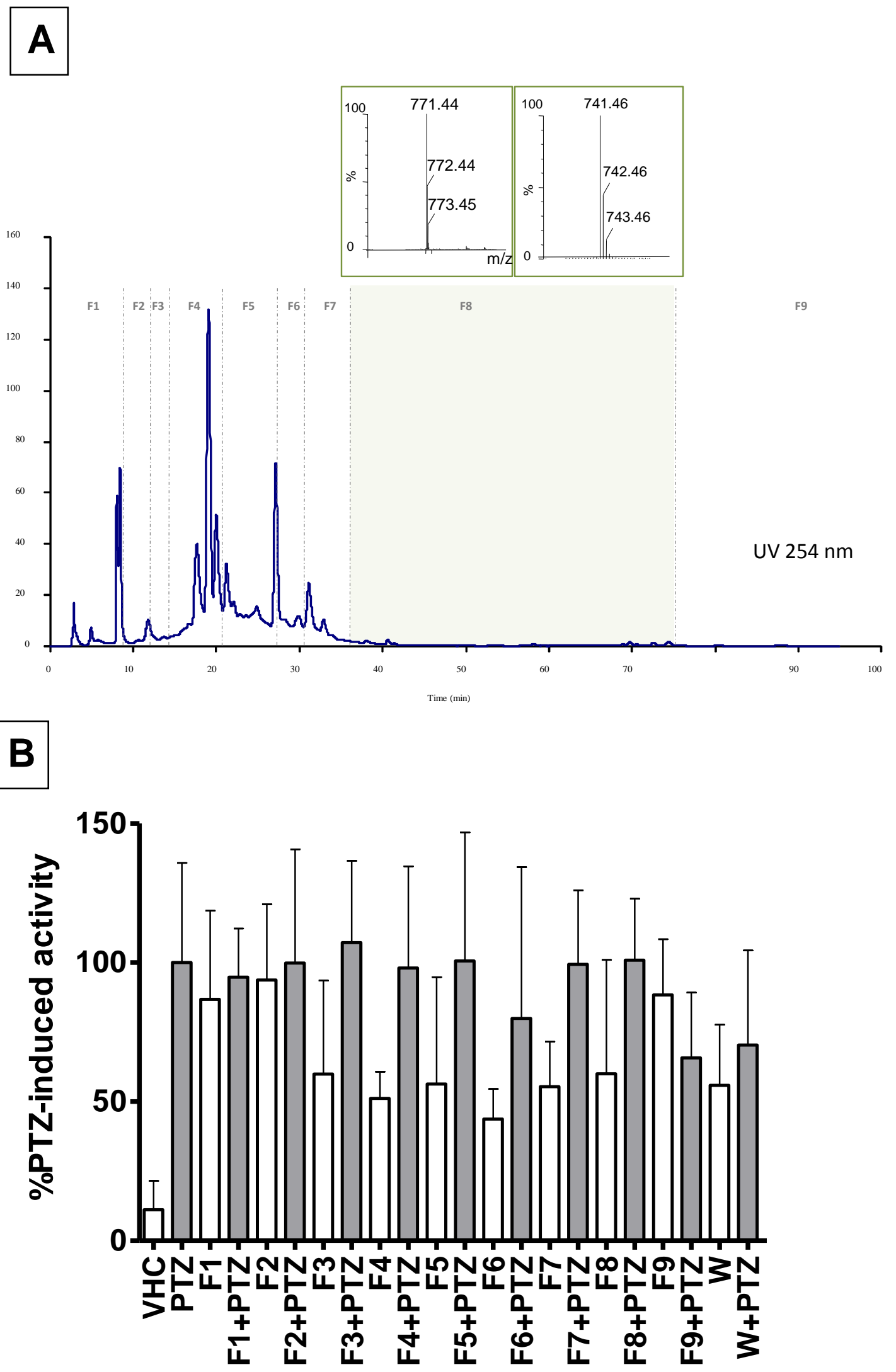

Figure 4 


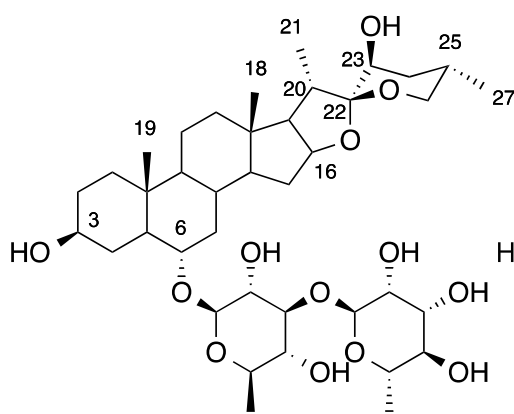

1. Torvoside J

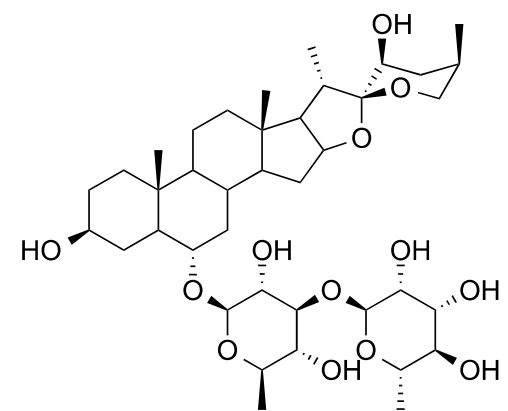

3. Torvoside $\mathrm{K}$

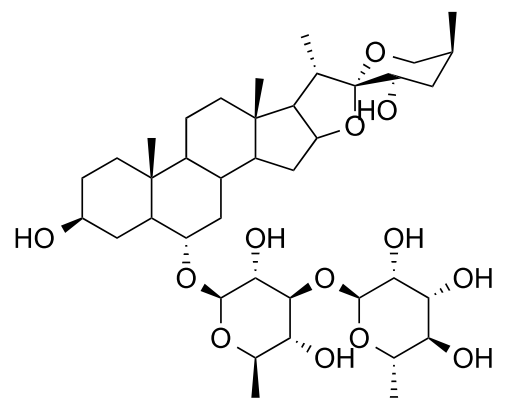

4. Paniculonin $B$<smiles>[R]C1C(=O)OC2CC1[C@@]1(C)CCC3C(C[C@H](O)C4C[C@@H](O)CC[C@]34C)C1C2</smiles>

2. Torvoside L

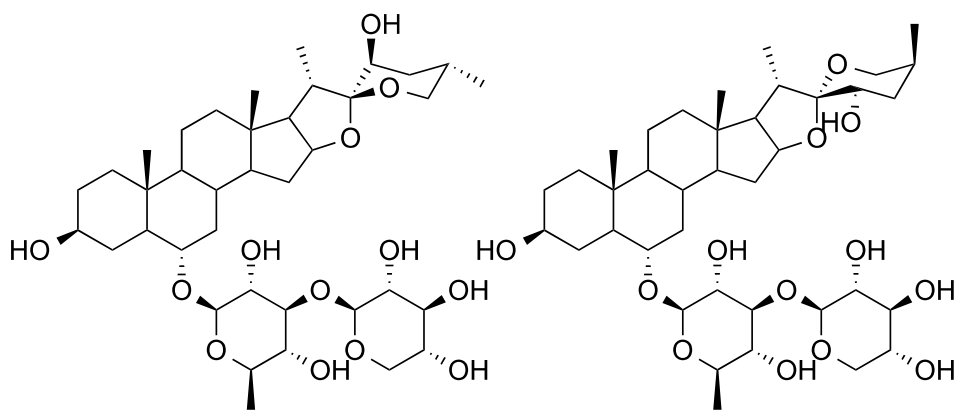

5

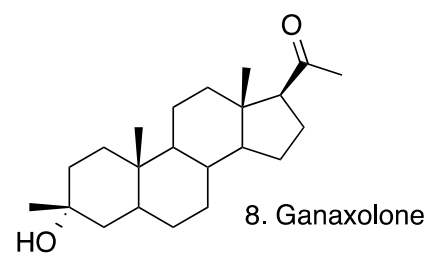




\section{Figure 5}

1

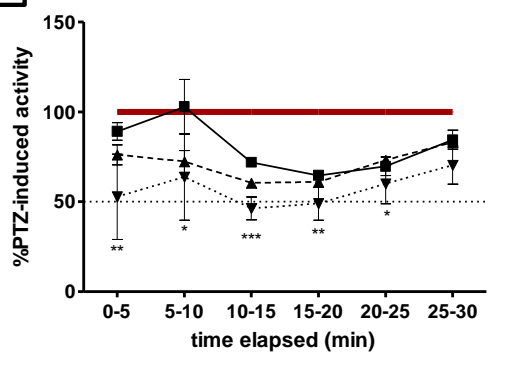

3

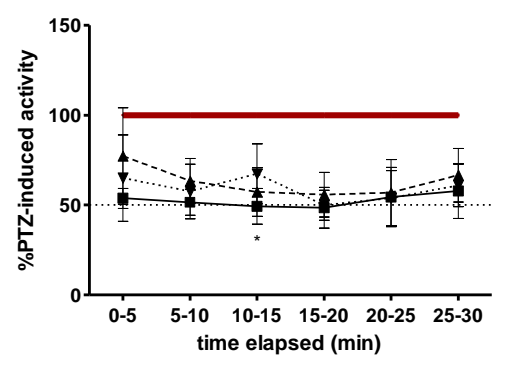

5
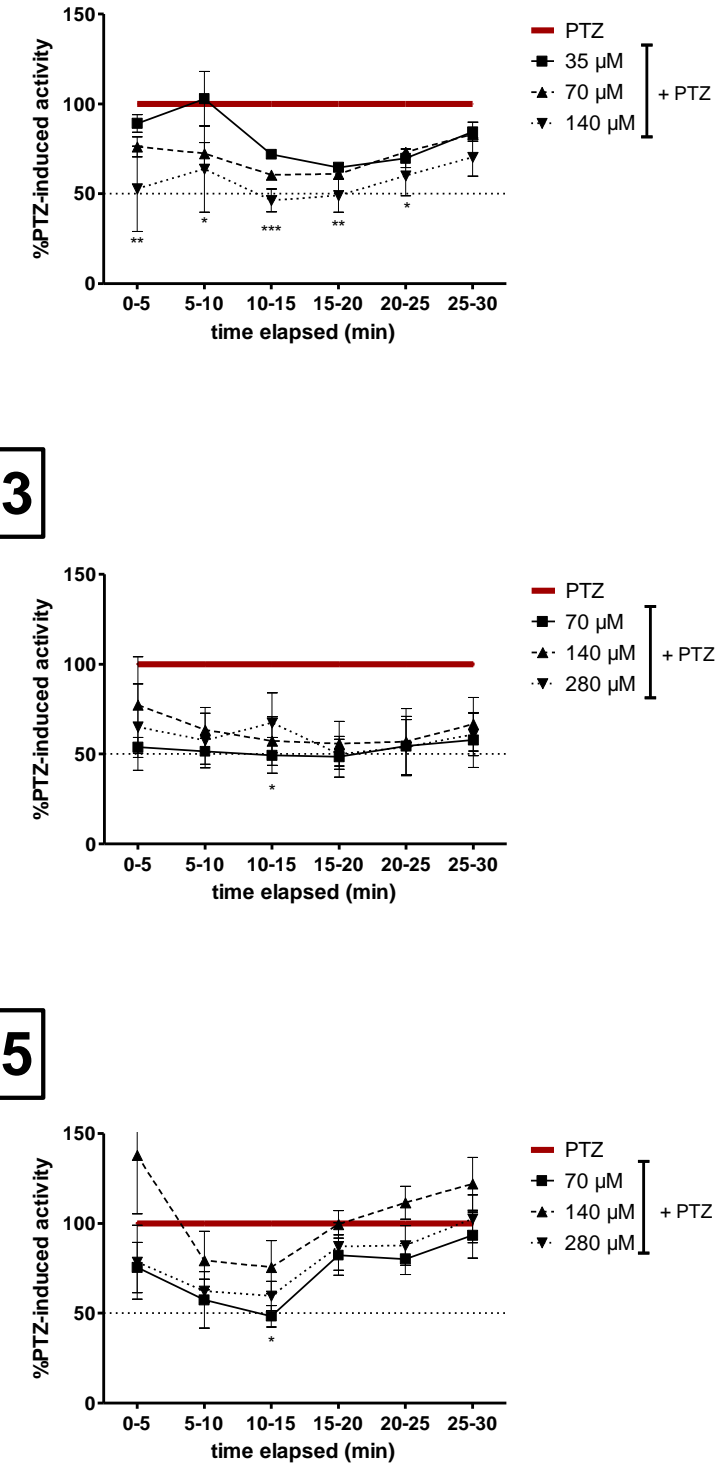

2

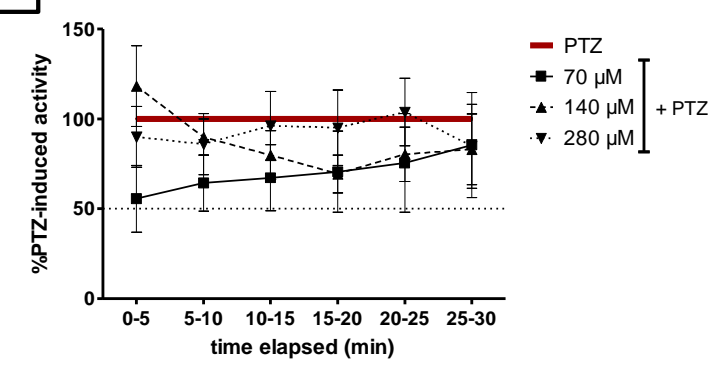

4
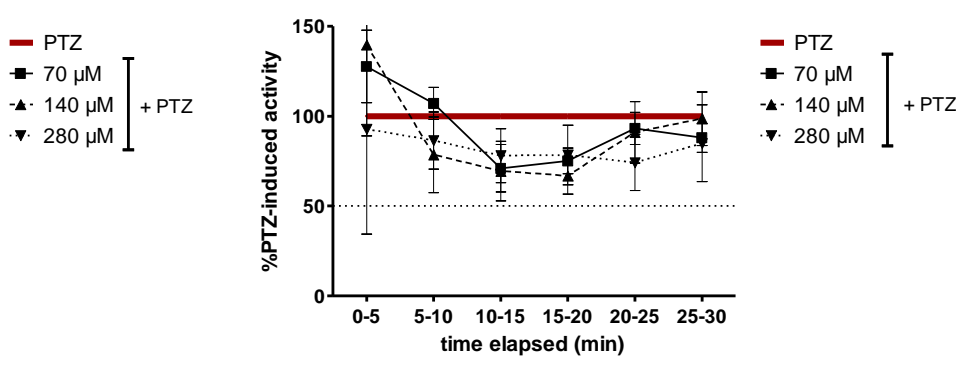

6

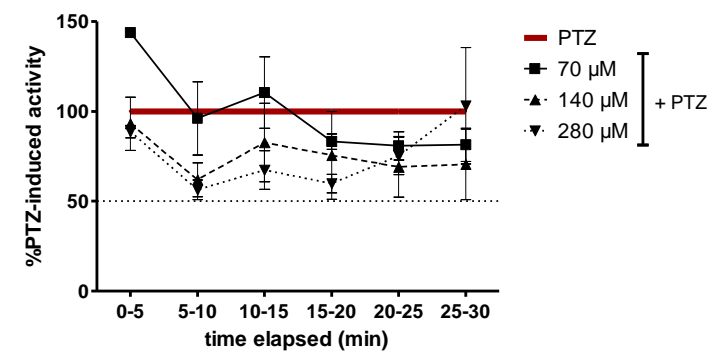

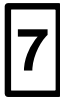

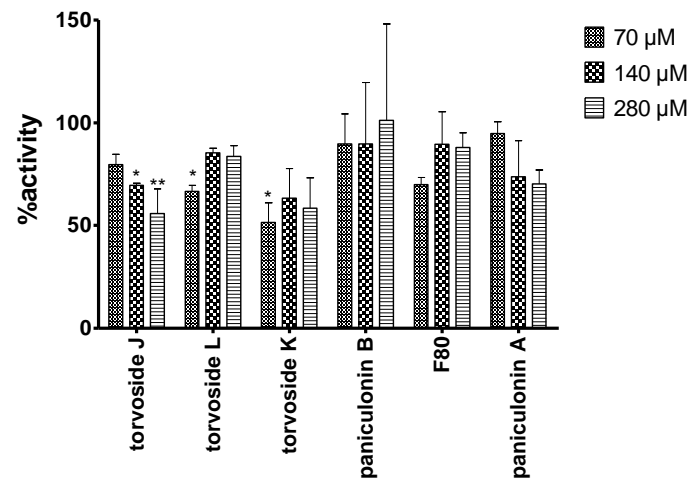


Figure 6

A

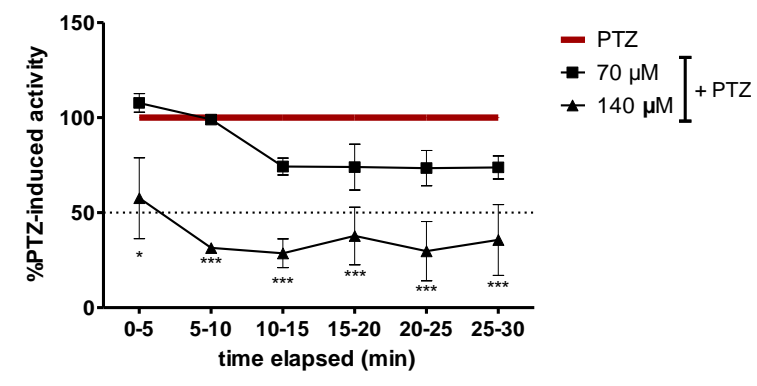

B

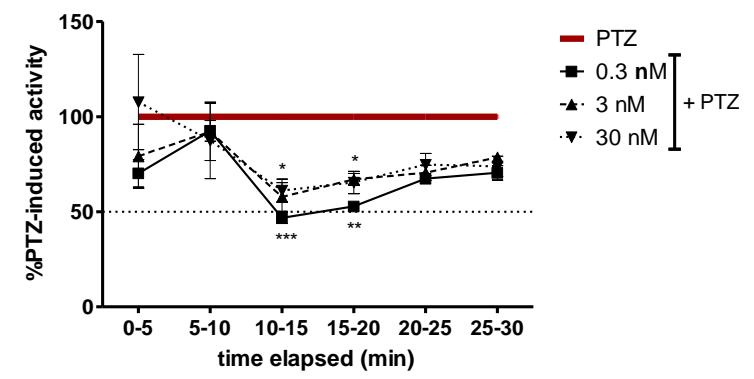

Figure 7
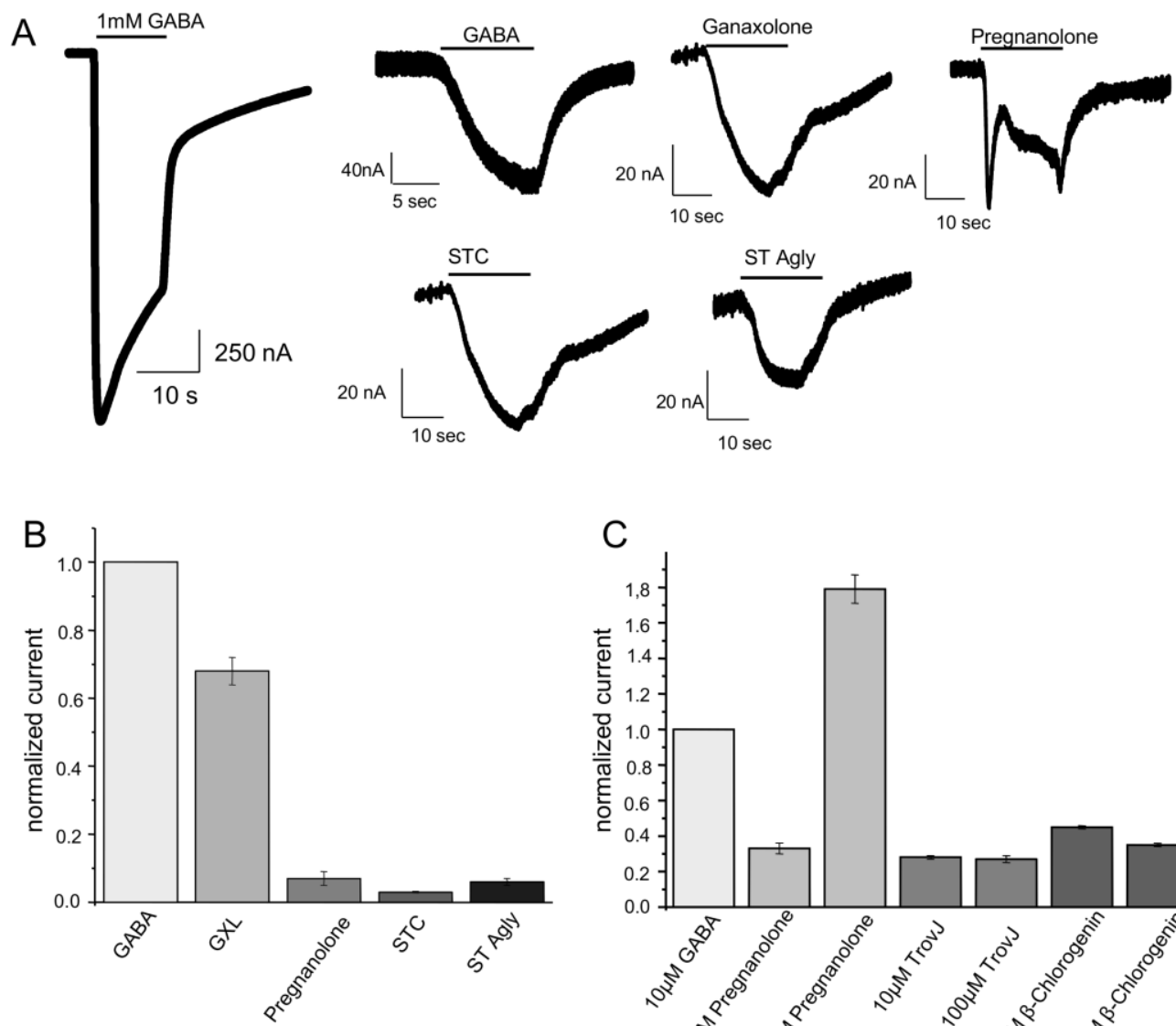

C

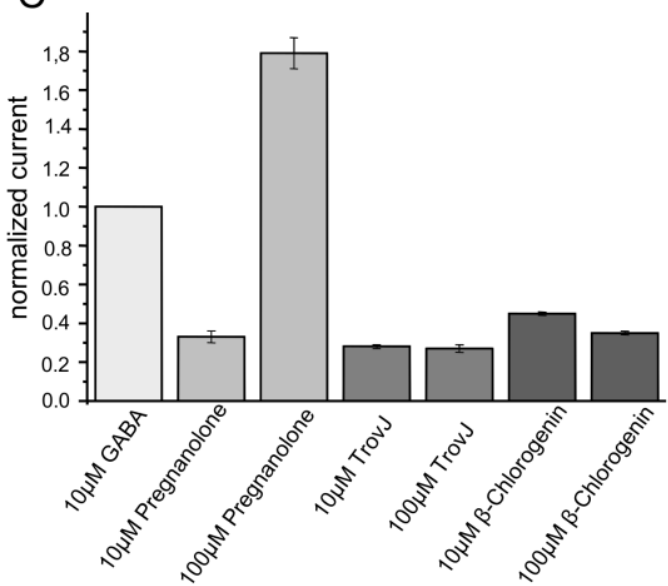

